\title{
A Case Study of Subtropical Frontogenesis during a Blocking Event
}

\author{
George TAi-Jen Chen \\ Department of Atmospheric Sciences, National Taiwan University, Taipei, Taiwan \\ Chung-Chieh WANG \\ Department of Atmospheric Sciences, Chinese Culture University, Taipei, Taiwan \\ AN-HSIANG WANG \\ National Science and Technology Center for Disaster Reduction (NCDR), Taipei, Taiwan
}

(Manuscript received 21 April 2006, in final form 6 October 2006)

\begin{abstract}
During 8-14 June 2000, a 500-hPa blocking event occurred over Mongolia and northern China (near $45^{\circ} \mathrm{N}, 108^{\circ} \mathrm{E}$ ), which was the only case over this region in June since 1981 . As the block developed, the initially weak low-level mei-yu front over southern China evolved into a system with strong baroclinity and subsequently moved south. The frontal passage over Taiwan caused temperatures to drop by $10^{\circ} \mathrm{C}$, the largest in June over two decades. Using gridded analyses, manually analyzed weather maps, and satellite and surface data, the present study investigates the evolution of this mei-yu front under the influence of the block. The $925-\mathrm{hPa}$ frontogenetical function is computed and effects of different processes are discussed. As the blocking event developed, concurrent ridge-trough amplification in the lower-midtroposphere produced a reversed thermal pattern. The lower-tropospheric high moved southward, and large-scale confluence and deformation were enhanced between the northerly flow and the prefrontal southwesterly flow. The location of the block, to the west-southwest of the Okhotsk Sea area, allowed it to affect the front over southern China and caused it to penetrate inside $20^{\circ} \mathrm{N}$, unusual for the month of June. The distribution of the frontogenetical function indicated that the mei-yu frontogenesis and the maintenance of the front were attributed to both deformation and convergence. These two processes together counteracted the strong frontolysis along the frontal zone from diabatic effects, caused by evaporative cooling of frontal precipitation on the warm side and stronger sensible heat transfer (and daytime heating over less cloudy areas) on the cold side of the front. When deformation, convergence, and diabatic effects were all combined, the net total frontogenesis peaked slightly ahead of the frontal zone, thus contributing to the southward propagation of the front in addition to the advection by postfrontal cold air in the present case. When the front moved into the South China Sea, the cross-frontal thermal gradient diminished rapidly, mainly due to the frontolytic effect from sensible heat flux over warm waters.
\end{abstract}

\section{Introduction}

Over Taiwan and southern China, climatologically there exists a relative rainfall maximum from mid-May to mid-June called the mei-yu season. During this period, repeated passages of mei-yu fronts bring persistent precipitation with frequent heavy rainfalls, leading to hazardous floods (Chen 1983; Lau et al. 1988). The

Corresponding author address: Prof. George Tai-Jen Chen, Department of Atmospheric Sciences, National Taiwan University, No. 61, Ln. 144, Sec. 4, Keelung Rd., 10772 Taipei, Taiwan.

E-mail: george@george2.as.ntu.edu.tw mean frontal position shifts northward with time, producing mei-yu rainfall over central China (and Baiu over Japan) roughly between mid-June and mid-July (Tao and Chen 1987; Ding 1992).

Chen and Tsay (1980) analyzed the mean atmospheric circulation during the mei-yu season in 1968-77 and found that major systems included 500-hPa high pressure $\left(\right.$ at $\left.50^{\circ}-70^{\circ} \mathrm{N}\right)$ located steadily at two regions: one near the Okhotsk Sea (at $150^{\circ} \mathrm{E}$; cf. Fig. 4a for location) and the other (near $75^{\circ} \mathrm{E}$ ) between the Ural Mountains and midSiberia. Chen (1994) compared wet and dry mei-yu seasons and found that the rainfall amount is largely controlled by the intensity and source

DOI: $10.1175 / M W R 3412.1$

(C) 2007 American Meteorological Society 
region of low-level flow, which are determined collectively by the position and strength of large-scale systems such as the east Asian trough, subtropical high (ridge), monsoon trough, and the blocking high over the Okhotsk Sea/eastern Siberia (Chen and Jou 1988). Thus, earlier synoptic-climatology studies indicated that blocking at mid- to high latitudes has an impact on mei-yu fronts near Taiwan.

Being a prominent and influential phenomenon, the upper-level blocking itself has been a long-time research topic, although a consensus in its definition has yet to be reached (e.g., Rex 1950, 1951; Lejenäs and Økland 1983; Pelly and Hoskins 2003). Northern Hemispheric blocking events are found most frequently in autumn and winter over three regions: The eastern North Atlantic-western Europe, the North Pacificwestern North America, and over land near the Ural Mountains (along $60^{\circ} \mathrm{E}$; Shukla and Mo 1983; Tibaldi et al. 1994; Pelly and Hoskins 2003). In the summer, blocking activity is also found near the Okhotsk Sea (e.g., Lejenäs and Økland 1983; Wang 1992; Ding et al. 2001). Major blocking episodes that last for at least $7-10$ days have strong regional preference and are often considered a result of interaction (resonance) between planetary standing waves and Rossby waves (e.g., Charney et al. 1981; Quiroz 1987; Lejenäs and Madden 1992; Nakamura et al. 1997). The less persistent ones (usually 1-3 days), on the other hand, travel slowly eastward and also occur along major storm tracks, and many studies have attributed their formation to baroclinic instability (e.g., Shukla and Mo 1983; Mullen 1987; Nakamura and Wallace 1993; Lupo and Smith 1998). Blocking events over the Okhotsk Sea are found by Japanese researchers to be mostly of the latter, less persistent type, but play an important role in initiating southward cold air surges and activating the Baiu (and mei-yu) front in Japan and central China (e.g., Ninomiya and Mizuno 1985, 1987; Ninomiya and Muraki 1986; Wang 1992). For southern China and Taiwan, however, the detailed relationship between blocking and the mei-yu front is not well known, especially in real cases, because the two regions of action are so distant and few case studies are available in the literature.

Chen (1993) studied mei-yu fronts over southern China using data collected during the Taiwan Area Mesoscale Experiment (TAMEX; Kuo and Chen 1990) in 1987 and found different large-scale circulation patterns and frontal characteristics before and after the seasonal transition in mid-June. Before the transition, westerlies prevailed throughout the troposphere and it was common for mei-yu fronts to possess appreciable baroclinity and penetrate into the subtropics (e.g., Chen et al. 1989; Trier et al. 1990; Chen and Hui 1990).
As the south Asian upper-level anticyclone shifted north associated with the transition, so did the baroclinic zone (Kato 1985; Ninomiya and Muraki 1986; Tao and Chen 1987; He et al. 1987). Afterward, the mei-yu (Baiu) started over the Yangtze River Valley and Japan, and as the season came to an end, fronts in southern China had strong moisture but only a weak temperature gradient (Chen and Chang 1980; Chen 1993).

On the mechanism of mei-yu frontogenesis, Chen and Hui (1992) employed the two-dimensional (2D) adiabatic equation of Miller (1948) and concluded that the horizontal deformation was the major frontogenetical forcing at $850 \mathrm{hPa}$ in a TAMEX case. Cho and Chen (1995) compared mei-yu fronts with typical cold fronts depicted by Hoskins and Bretherton (1972) and suggested that mei-yu fronts might be quite reminiscent of traditional cold fronts at early stages, but their baroclinity would be reduced as they moved over warmer surfaces (also Trier et al. 1990; Chen 1993).

During 11-13 June 2000, a mei-yu front passed over Taiwan and brought heavy rainfall to the island. Weather maps at $500 \mathrm{hPa}$ revealed that an upper-level blocking pattern developed near $45^{\circ} \mathrm{N}, 108^{\circ} \mathrm{E}$ over Mongolia and northern China by 12 June (to be described in section 3a). Using twice-daily Japan Meteorological Agency (JMA) weather maps and the criteria of Wang (1992), we found that this was the only blocking event at the same region in June during 1981-2000.

Figure 1 presents manually analyzed surface maps, where the frontal position was determined mainly based on temperatures (at the southern edge of a strong gradient) with supplementary information from winds. On 8 June, the thermal gradient over southern China was weak to moderate at $1^{\circ}-2.5^{\circ} \mathrm{C}(100 \mathrm{~km})^{-1}$ (Fig. 1a), but increased significantly to reach $3^{\circ}-6^{\circ} \mathrm{C}(100 \mathrm{~km})^{-1}$ and a maximum cross-frontal contrast of $16^{\circ} \mathrm{C}$ at 1200 UTC 10 June (Fig. 1b), larger than those found in earlier studies (Chen et al. 1989; Chen and Hui 1990, 1992; Trier et al. 1990). The baroclinity remained strong on 11 June (not shown) but eventually weakened on 13 June after the front passed Taiwan and entered the South China Sea (Fig. 1c). During this period, a station near $27^{\circ} \mathrm{N}, 113^{\circ} \mathrm{E}$ was consistently $3^{\circ}-7^{\circ} \mathrm{C}$ colder than the surrounding area, a result likely linked to topography to some extent (cf. Fig. 2). Nevertheless, the temperature at this site also decreased by $9^{\circ} \mathrm{C}$ from Figs. 1a to $1 \mathrm{~b}$ as the strong mei-yu frontogenesis took place.

As shown in Fig. 3, after the frontal passage air temperatures dropped by at least $10^{\circ} \mathrm{C}$ at many stations over Taiwan, including Taipei, Taichung, Tainan, and Hengchun (cf. Fig. 2). The lowest temperatures on 13 June were below or near $20^{\circ} \mathrm{C}$, and $4^{\circ}-6^{\circ} \mathrm{C}$ lower than the monthly mean of June. The 3-day decrease in daily 

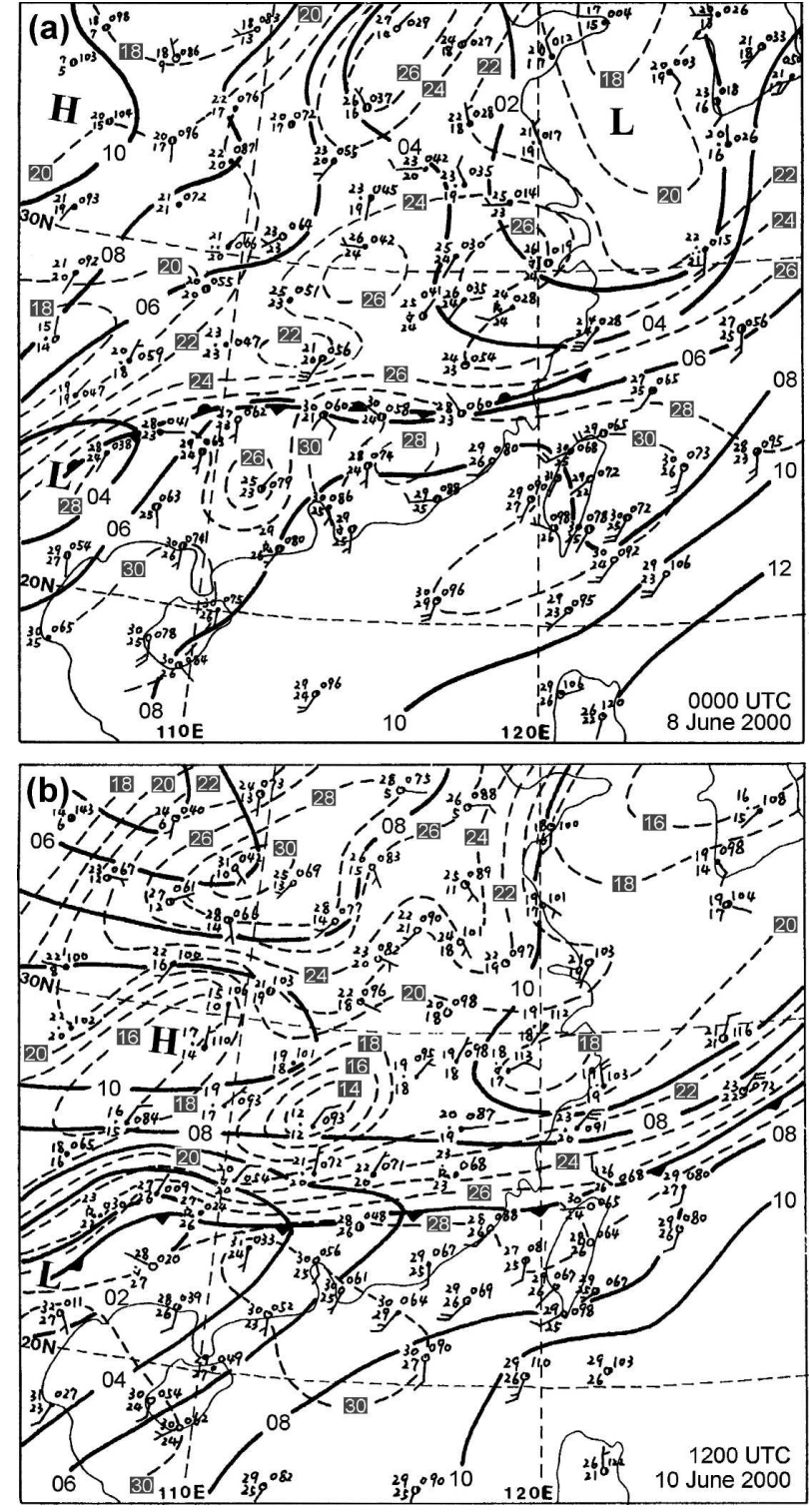

mean temperatures at these 4 sites (from north to south) was $9.5^{\circ}, 9.3^{\circ}, 7.2^{\circ}$, and $6.7^{\circ} \mathrm{C}$, respectively. Using $6.5^{\circ} \mathrm{C}$ as the criterion at all 4 stations, Table 1 lists qualified events from 1981 to 2000, merely 12 of them. Again, the present case was the only one in June, while all others occurred during November-April. Thus, under the influence of a rare $500-\mathrm{hPa}$ block, this mei-yu front case was itself quite unusual, being able to reach such a strong baroclinity and penetrate inside $20^{\circ} \mathrm{N}$, so far into the subtropics (cf. Fig. 1c). This case, therefore, offers a unique opportunity to understand the interaction between subtropical mei-yu fronts and their largerscale environment during a blocking event over Mongolia and northern China. The purpose of this study, hence, is to examine the development and evolution of

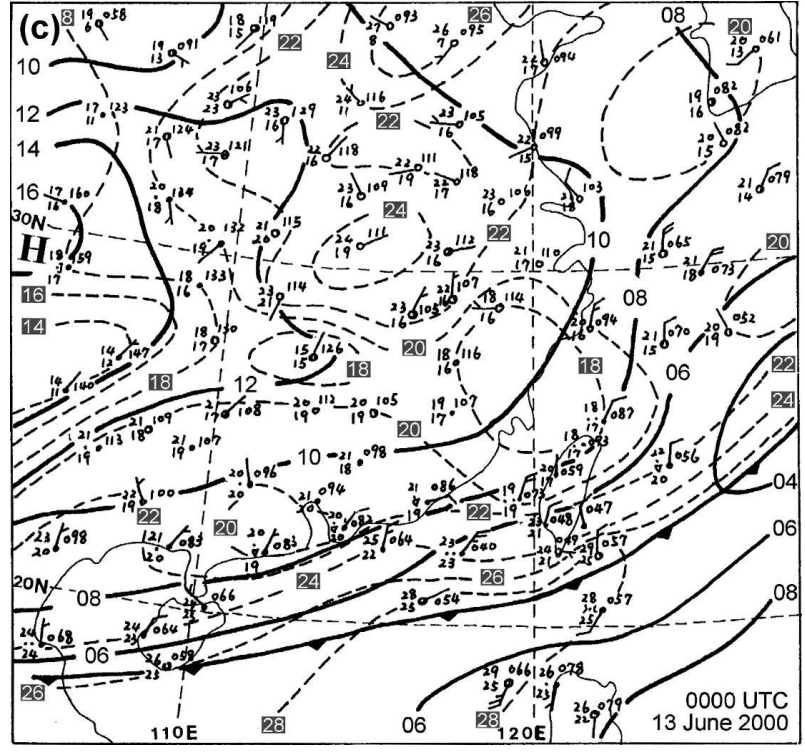

FIG. 1. Mean sea level pressure (hPa) and temperature $\left({ }^{\circ} \mathrm{C}\right)$ analyses at (a) 0000 UTC 8 Jun, (b) 1200 UTC 10 Jun, and (c) 0000 UTC 13 Jun 2000. Contour intervals are $2 \mathrm{hPa}$ for pressure and $2{ }^{\circ} \mathrm{C}$ for temperature, respectively, and surface frontal position is shown. this mei-yu front under the influence of the block. The mechanism of frontogenesis and effects from various processes, including diabatic ones, are also diagnosed and discussed through a calculation of the frontogenetical function of Ninomiya (1984).

\section{Data and methodology}

\section{a. Data and subjective analysis}

Five data sources were used in the present study. First, surface weather maps at 0000 and 1200 UTC from the Central Weather Bureau of Taiwan with pressure and temperature fields subjectively analyzed were used for the discussion of synoptic conditions. Second, gridded objective analyses from the European Centre for 


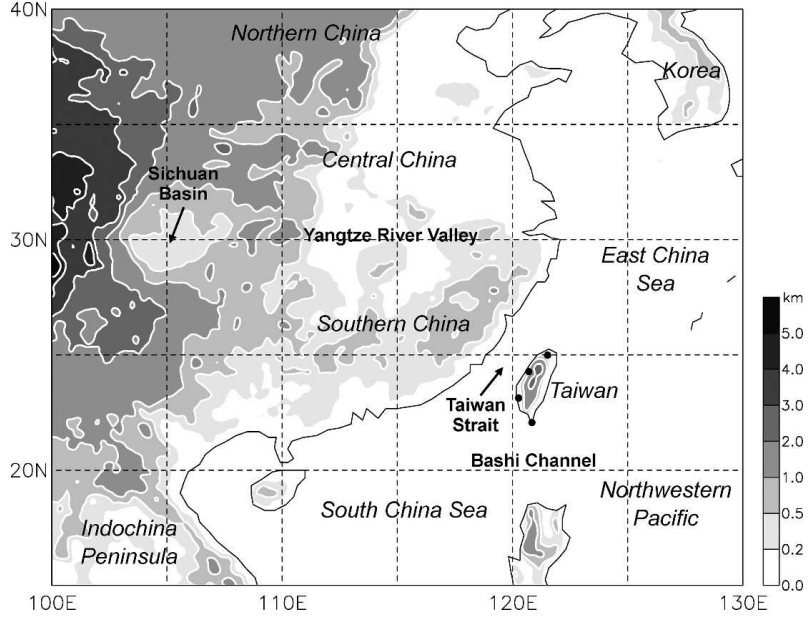

FIG. 2. Smoothed topography (shading; km) over east Asia, with the shading scale shown at the lower right corner. Geographical features used in the text are indicated. The locations of four selected stations over Taiwan (from north to south: Taipei, Taichung, Tainan, and Hengchun) used in Fig. 3 and Table 1 are marked with solid dots.

Medium-Range Weather Forecasts (ECMWF) in Tropical Ocean Global Atmosphere (TOGA) format were employed for both synoptic discussion and frontogenetical function calculation. The resolution of this dataset is $1.125^{\circ}$ latitude-longitude and $6 \mathrm{~h}$ at 21 pressure $(p)$ levels, and the variables provided include the geopotential height, temperature, $u$ and $v$ components of horizontal wind, relative humidity, and vertical velocity $(\omega)$. Third, hourly infrared (IR) blackbody brightness temperature data from the Japanese Geosta- tionary Meteorological Satellite-5 (GMS-5) were used for cloud identification. Fourth, 500-hPa weather maps (every $12 \mathrm{~h}$ ) from JMA in June and last daily (and hourly) temperature sequences at selected stations in Taiwan, both during 1981-2000, were reviewed to assess the rareness of the blocking and mei-yu front studied here, as presented in section 1 .

\section{b. Calculation of frontogenetical function}

For the evaluation of frontogenesis, the 2D frontogenetical function first defined by Petterssen (1936) and formulated by Ninomiya (1984) on $p$ coordinates was chosen as

$$
F \equiv \frac{d}{d t}\left|\nabla_{H} \theta\right|=\mathrm{FG} 1+\mathrm{FG} 2+\mathrm{FG} 3+\mathrm{FG} 4,
$$

where the four forcing terms at the right-hand side, respectively, are

$$
\begin{aligned}
\mathrm{FG} 1= & \frac{1}{\left|\boldsymbol{\nabla}_{H} \theta\right|}\left[\boldsymbol{\nabla}_{H} \theta \cdot \nabla_{H}\left(\frac{d \theta}{d t}\right)\right], \\
\mathrm{FG} 2= & -\frac{1}{2\left|\boldsymbol{\nabla}_{H} \theta\right|}\left[\left(\frac{\partial \theta}{\partial x}\right)^{2}+\left(\frac{\partial \theta}{\partial y}\right)^{2}\right]\left(\frac{\partial u}{\partial x}+\frac{\partial v}{\partial y}\right), \\
\mathrm{FG} 3= & -\frac{1}{\left|\boldsymbol{\nabla}_{H} \theta\right|}\left\{\frac{1}{2}\left[\left(\frac{\partial \theta}{\partial x}\right)^{2}-\left(\frac{\partial \theta}{\partial y}\right)^{2}\right]\left(\frac{\partial u}{\partial x}-\frac{\partial v}{\partial y}\right)\right. \\
& \left.+\frac{\partial \theta}{\partial x} \frac{\partial \theta}{\partial y}\left(\frac{\partial v}{\partial x}+\frac{\partial u}{\partial y}\right)\right\},
\end{aligned}
$$

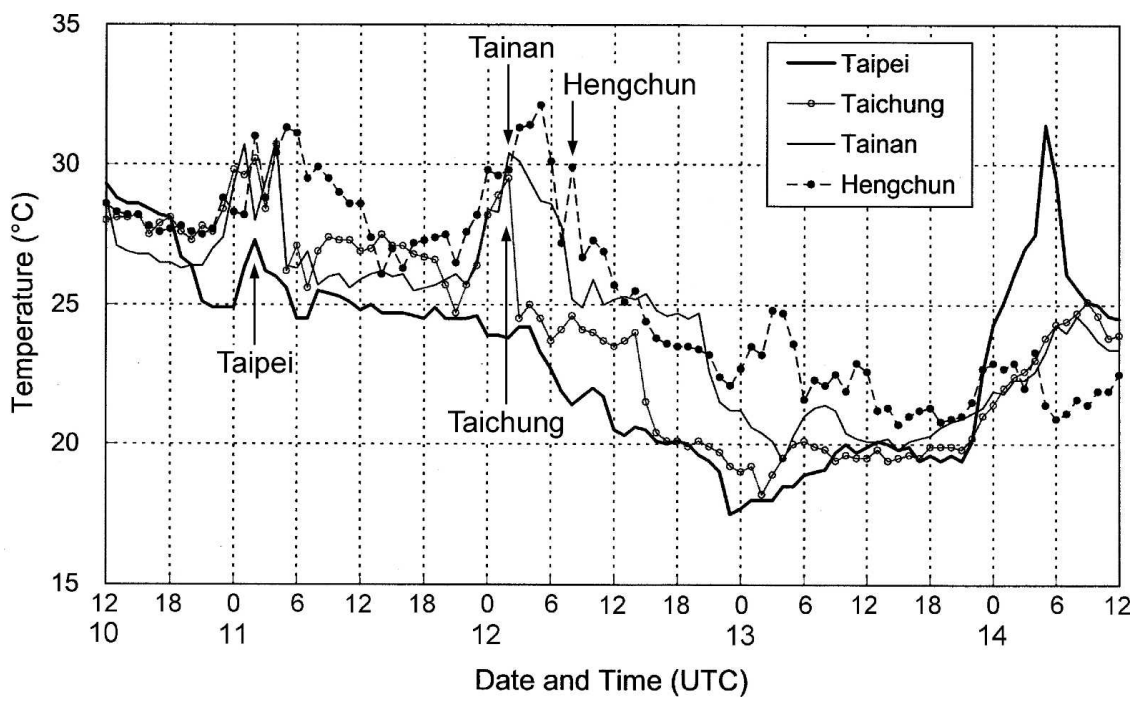

FIG. 3. Hourly temperature $\left({ }^{\circ} \mathrm{C}\right)$ time series at four selected surface stations in Taiwan: Taipei, Taichung, Tainan, and Hengchun (from north to south; see Fig. 2 for locations) from 1200 UTC 10 Jun to 1200 UTC 14 Jun 2000. The arrows indicate the time of frontal passage at each of the four stations. In Taiwan, 0000 UTC corresponds to 0800 LST. 
TABLE 1. List of all events from 1981 to 2000 with 3-day decreases in the daily mean temperature of at least $6.5^{\circ} \mathrm{C}$ at all four surface stations in Taiwan: Taipei, Taichung, Tainan, and Hengchun (see Fig. 2 for locations). Events that satisfied more than one 3-day period consecutively are marked by an asterisk, and those where not all four stations met the requirement during the same 3-day period are marked by a pound symbol (the current event).

\begin{tabular}{clrl}
\hline \hline No. & \multicolumn{1}{c}{ Event period } & No. & \multicolumn{1}{c}{ Event period } \\
\hline 1 & 2-6 Mar 1983* & 7 & 23-26 Mar 1995 \\
2 & 29 Dec 1985-1 Jan 1986 & 8 & 30 Mar-3 Apr 1996* \\
3 & 23-26 Mar 1987 & 9 & 18-21 Apr 1996 \\
4 & 3-6 Mar 1989 & 10 & 1-4 Feb 1999 \\
5 & 26-29 Dec 1991 & 11 & 24-27 Jan 2000 \\
6 & 18-21 Nov 1992 & 12 & 10-14 Jun 2000 \\
\hline
\end{tabular}

and

$$
\mathrm{FG} 4=-\frac{1}{\left|\nabla_{H} \theta\right|}\left[\frac{\partial \theta}{\partial p}\left(\frac{\partial \theta}{\partial x} \frac{\partial \omega}{\partial x}+\frac{\partial \theta}{\partial y} \frac{\partial \omega}{\partial y}\right)\right] .
$$

In Eqs. (1)-(5), $\theta$ is potential temperature and $\boldsymbol{\nabla}_{H}$ is the horizontal gradient operator $[(\partial / \partial x) \mathbf{i}+(\partial / \partial y) \mathbf{j}$, where $\mathbf{i}$ and $\mathbf{j}$ are unit vectors in $x$ and $y$ directions, respectively]. The terms FG1, FG2, FG3, and FG4 represent effects from diabatic processes, horizontal convergence, deformation, and tilting, respectively, while FG3 includes both stretching $(\partial u / \partial x-\partial v / \partial y)$ and shearing $(\partial v / \partial x+\partial u / \partial y)$ deformation.

The total derivative $(d / d t)$ in Eqs. (1) and (2) is defined, and evaluated, as

$$
\frac{d}{d t}=\frac{\partial}{\partial t}+u \frac{\partial}{\partial x}+v \frac{\partial}{\partial y}+\omega \frac{\partial}{\partial p},
$$

while the central finite-difference method was used to compute the advection terms. The local tendency $(\partial / \partial t)$, on the other hand, is evaluated using the cubic spline fitting function (Shikin and Plis 1995, their section 1.1) because of the inadequacy of 6-hourly data in resolving diurnal and higher-frequency variations in $\theta$. In principle, the method fits the time series of a function (at evenly spaced points) using cubic polynomials, which are then used to approximate values at a higher temporal resolution. This method, also adopted by Sinclair and Elsberry (1986), takes the nonlinearity of variables and their first derivatives into account and can reduce error as compared with linear interpolation. Thus, values $\left(\theta\right.$ or $\left.\left|\nabla_{H} \theta\right|\right)$ at 1 -h intervals were first obtained from ECMWF data, and local tendencies were evaluated using finite difference. The resultant difference (residual) between total $F$ as computed from $d\left|\nabla_{H} \theta\right| / d t$ in Eq. (1) and the sum of FG1-FG4 in Eqs. (2)-(5) was significantly reduced, an indication that the cubic spline function indeed provided more accurate approximation for local tendency than linear interpolation. Because our primary interests were in the evolution of the meiyu front near the surface, the frontogenetical function was calculated at 925 and $1000 \mathrm{hPa}$, following the method described above. At these levels, the vertical advection term in Eq. (6) was one order of magnitude smaller than the other terms because of small vertical velocity, and it is therefore neglected.

\section{Synoptic-scale evolution of the blocking event and mei-yu front}

\section{a. 500-hPa analyses}

The ECMWF analyses at $500 \mathrm{hPa}$ clearly depict the evolution of the blocking event (Fig. 4). At 0000 UTC 8 June, the east Asian main trough was over northeastern China with strong cyclonic vorticity, and a migratory trough was over eastern central China (Fig. 4a). A ridge existed near $51^{\circ} \mathrm{N}, 111^{\circ} \mathrm{E}$ and northwesterly flow prevailed over northern and central China with confluence. The JMA Northern Hemispheric 500-hPa map on 8 June (not shown) shows a deep upstream low near $60^{\circ} \mathrm{N}, 80^{\circ} \mathrm{E}$ and a train of prominent midlatitude highs/ ridges and lows/troughs encircling almost the entire globe, with a wavenumber of roughly 6.5. On 10 June (Fig. 4b), the ridge over Mongolia amplified and extended northeastward toward the Okhotsk Sea, and the main trough also deepened. The two troughs merged on 11 June, and a closed blocking high (5830 gpm) began to form at $45^{\circ} \mathrm{N}, 105^{\circ} \mathrm{E}$ (not shown).

At 0000 UTC 12 June (Fig. 4c), the 500-hPa ridgetrough system continued to amplify, and the blocking high reached its maximum strength with a clear "omega" shape. With a central value of $5880 \mathrm{gpm}$ at $45^{\circ} \mathrm{N}, 108^{\circ} \mathrm{E}$, the high occupied all of Mongolia and northern China. A cutoff low also formed over Korea, while northeasterly winds reaching $20 \mathrm{~m} \mathrm{~s}^{-1}$ prevailed between the ridge and the trough. Over central China, large-scale confluence clearly existed near the southward-moving trough, which was already vertically coupled with the low-level mei-yu front (to be shown later). By 13 June (Fig. 4d), the block had started to weaken and move southward, and the associated eastward-extending ridge also diminished rapidly. On the other hand, the trough kept moving southward and the northerly flow behind remained strong. At this time, relative vorticity associated with the trough over southeastern China and the block reached 7 and $-10 \times 10^{-5} \mathrm{~s}^{-1}$, respectively (Fig. 4d). The evolution of the blocking event could be divided into four stages: formation ( 8 June), intensification (9-11 June), mature 
$500 \mathrm{hPa} \mathrm{Z/UV/VORT} 2000$ Jun 8 00Z

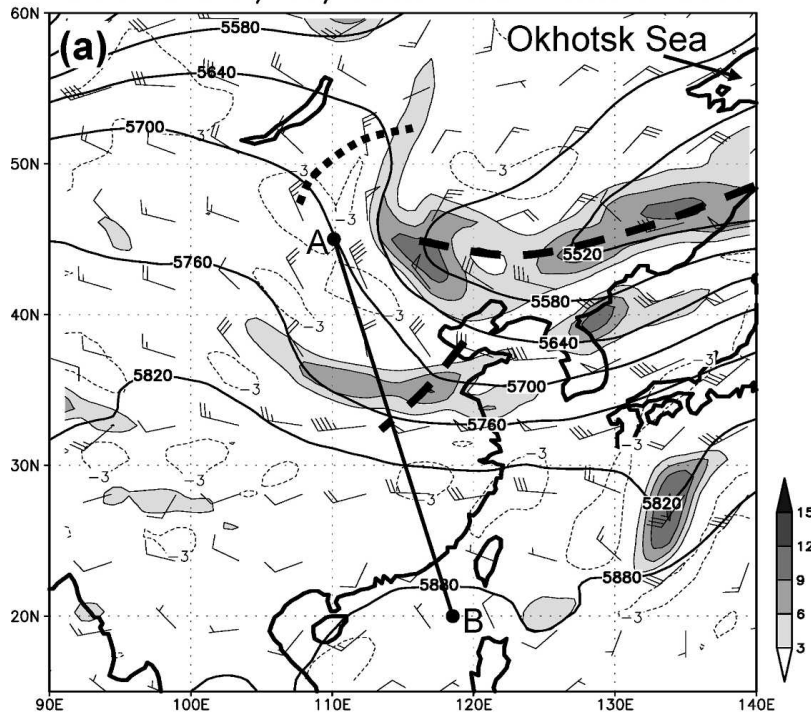

$500 \mathrm{hPa}$ Z/UV/VORT 2000 Jun 12 00Z

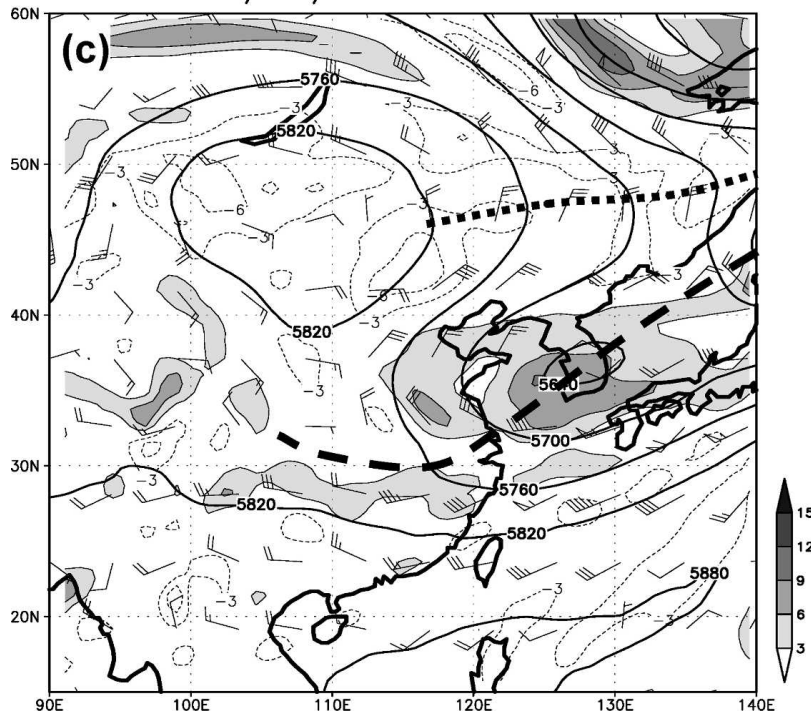

$500 \mathrm{hPa} \mathrm{Z/UV/VORT} 2000$ Jun 10 00Z

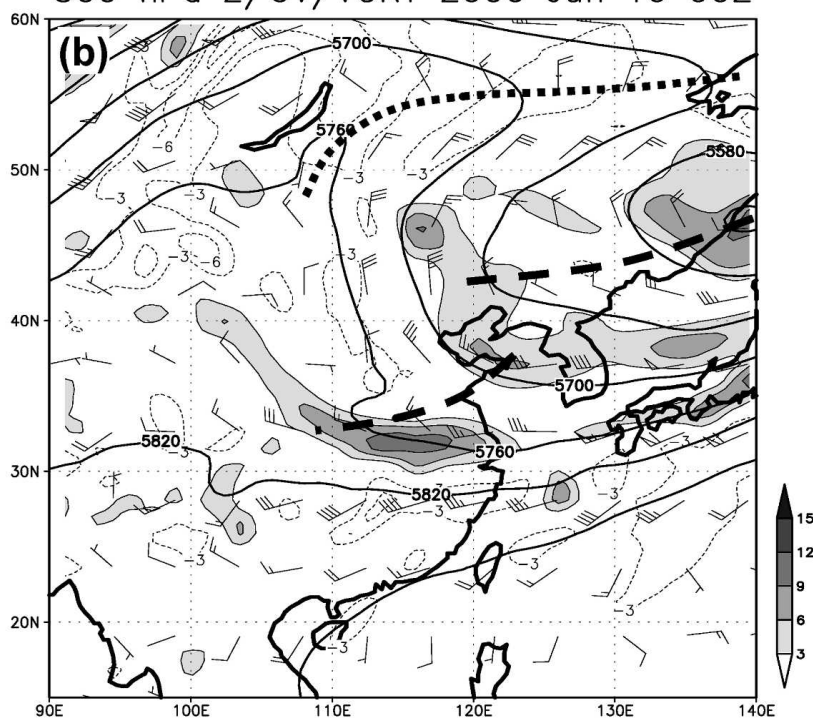

$500 \mathrm{hPa} \mathrm{Z/UV/VORT} 2000$ Jun 13 00Z

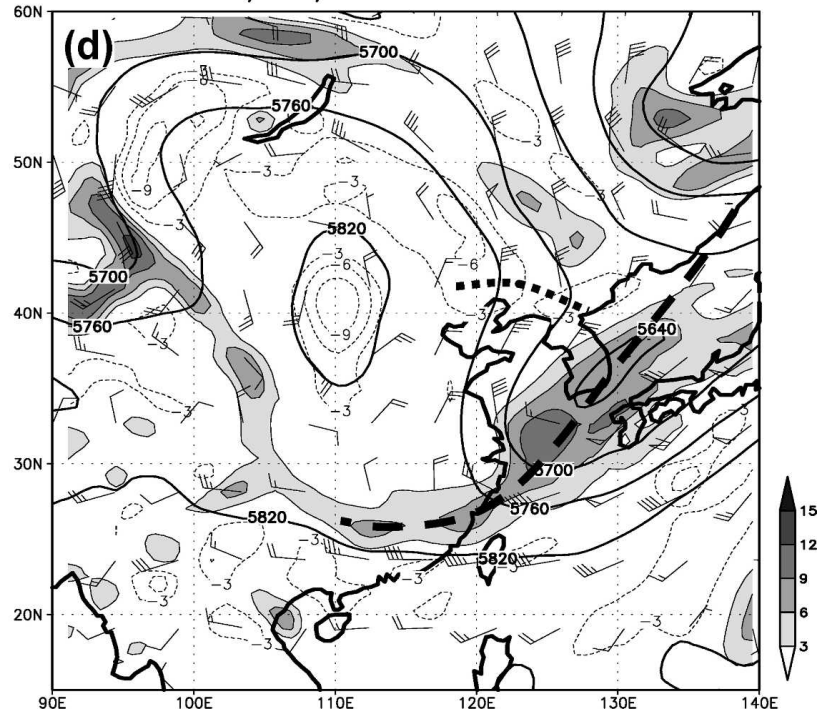

FIG. 4. The 500-hPa ECMWF analyses of geopotential height (gpm; solid), relative vorticity $\left(10^{-5} \mathrm{~s}^{-1}\right.$; solid with shading for positive and dashed for negative values), and horizontal winds $\left(\mathrm{m} \mathrm{s}^{-1}\right.$ ) at 0000 UTC (a) 8 Jun, (b) 10 Jun, (c) 12 Jun, and (d) 13 Jun 2000. Contour (shading) intervals are $60 \mathrm{gpm}$ for geopotential height and $3 \times 10^{-5} \mathrm{~s}^{-1}$ (zero line omitted) for relative vorticity. For winds, full (half) barbs represent 5 (2.5) $\mathrm{m} \mathrm{s}^{-1}$, and thick dashed (dotted) lines indicate the trough (ridge). In (a), line $\mathrm{A}-\mathrm{B}$ (from $45^{\circ} \mathrm{N}, 110^{\circ} \mathrm{E}$ to $20^{\circ} \mathrm{N}, 118.3^{\circ} \mathrm{E}$ ) depicts the vertical cross section used in Fig. 7 , and the western tip of the Okhotsk Sea is indicated.

(12 June), and weakening (13-14 June) stages, and synoptic conditions at other levels are discussed in the following subsections accordingly.

\section{b. Jet-level analyses}

Figures $5 \mathrm{a}-\mathrm{c}$ show that from formation to mature stages of the blocking event, both the east Asian main trough and the ridge associated with the block in the upper troposphere amplified rapidly. Between the ridge and the trough, strong northerly flow existed at
$200 \mathrm{hPa}$, and large-scale confluence similar to that which occurred at $500 \mathrm{hPa}$ also became increasingly evident over central China. Accompanying the amplification of this ridge-trough system, the baroclinic zone, characterized by a large geopotential height gradient and upper-level jet (ULJ), migrated southward. As the surface front passed Taiwan on 13 June, the upper-level baroclinic zone also moved into southern China (Fig. 5d). Judging from the 200-hPa flow pattern, the present case occurred before seasonal transition 

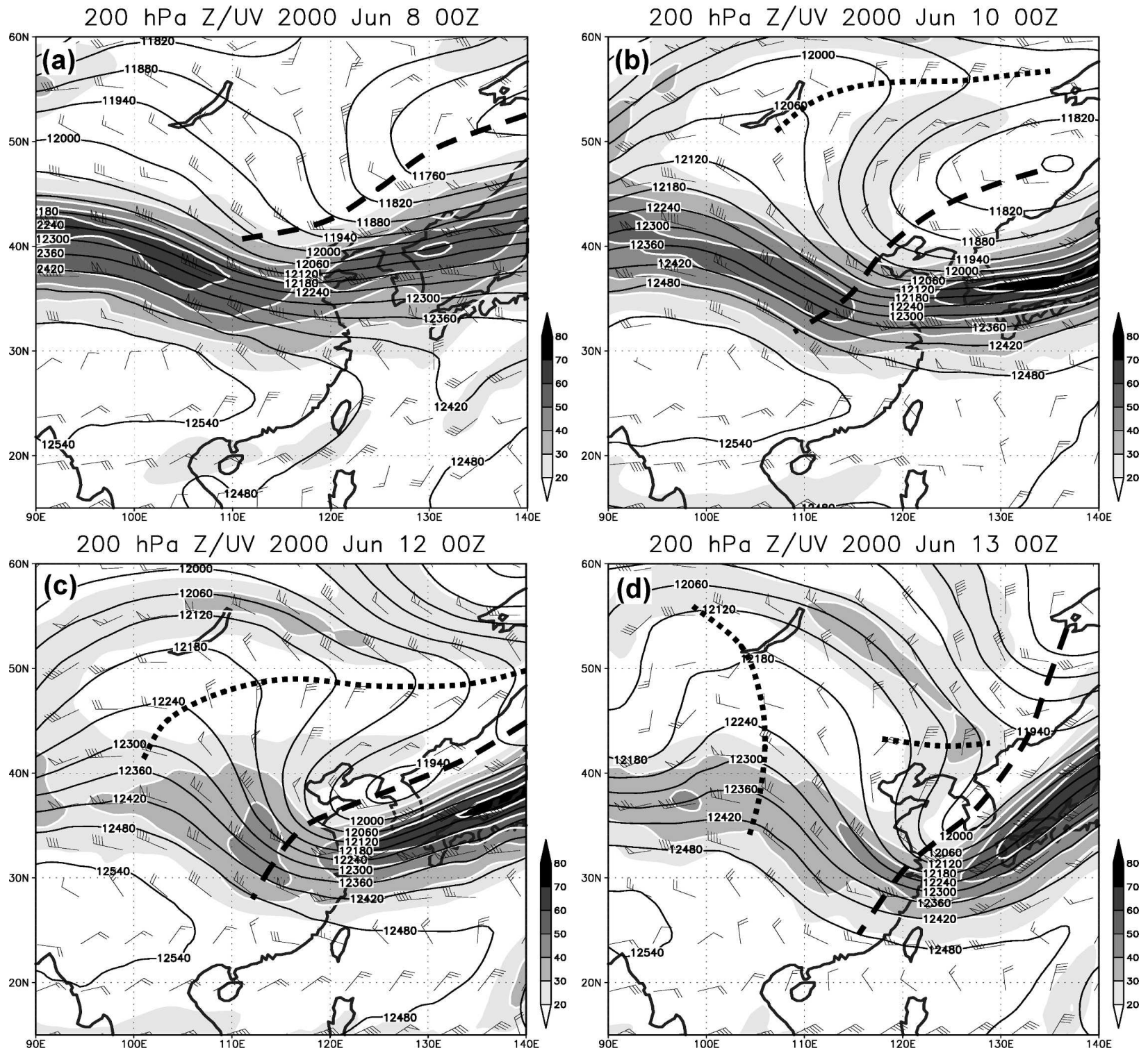

FIG. 5. The 200-hPa ECMWF analyses of geopotential height (gpm; solid) and horizontal winds ( $\mathrm{m} \mathrm{s}^{-1}$; with wind speed shaded) at 0000 UTC (a) 8 Jun, (b) 10 Jun, (c) 12 Jun, and (d) 13 Jun 2000. Contour intervals are 60 gpm for geopotential height, and full (half) barbs represent $5(2.5) \mathrm{m} \mathrm{s}^{-1}$ for winds. Thick dashed (dotted) lines indicate the trough (ridge).

(Chen 1993), but the intensity of the trough-jet system still constituted a rare event.

\section{c. Surface and low-level analyses}

On 8 June when no significant feature appeared aloft (cf. Fig. 4a), over southern China there preexisted a stationary surface mei-yu front, extending from $27^{\circ} \mathrm{N}$, $122^{\circ} \mathrm{E}$ to the low near $23^{\circ} \mathrm{N}, 105^{\circ} \mathrm{E}$ (Fig. 1a). As discussed in section 1, this east-northeast-west-southwestoriented front was associated with weak-to-moderate thermal gradient. As the block intensified at 1200 UTC 10 June, the front extended farther to the east and started to move southward slowly, while the associated baroclinity reached a maximum (Fig. 1b). Behind the front, northeasterly flow prevailed both over land and ocean. The pressure gradient across the front also strengthened, and a closed cold high $(1012 \mathrm{hPa})$ developed near $29^{\circ} \mathrm{N}, 108^{\circ} \mathrm{E}$ (hereafter referred to as the Sichuan high). North of $30^{\circ} \mathrm{N}$ over central China, in contrast, southerly winds existed and air temperatures reached $26^{\circ}-30^{\circ} \mathrm{C}$. During $11-12$ June as the block gradually matured, the Sichuan high remained stationary and the front kept advancing southward (not shown). On 13 June (Fig. 1c), the surface front entered 
$700 \mathrm{hPa} \mathrm{Z} / \mathrm{UV} / \mathrm{T} 2000$ Jun $10 \mathrm{OOZ}$

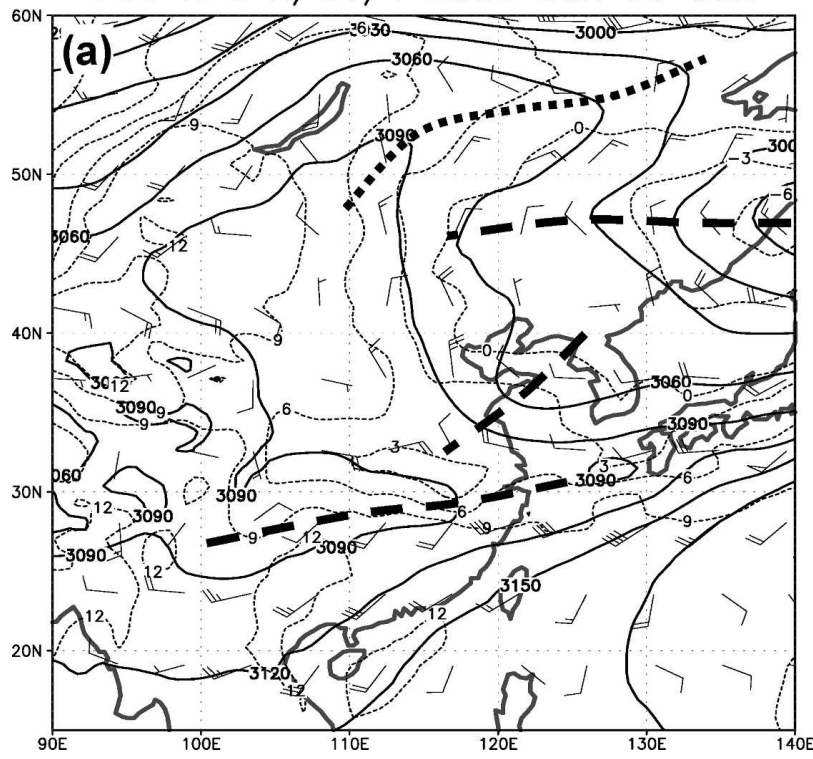

$700 \mathrm{hPa} \mathrm{Z} / \mathrm{UV} / \mathrm{T} 2000$ Jun $1200 \mathrm{Z}$

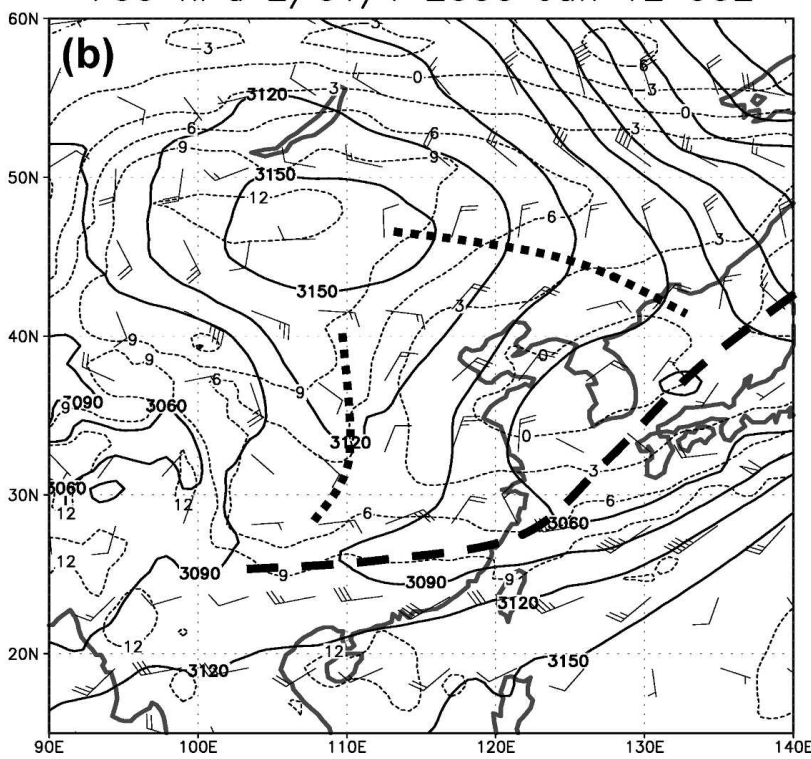

FIG. 6. The 700-hPa ECMWF analyses of geopotential height (gpm; solid), temperature $\left({ }^{\circ} \mathrm{C}\right.$; dashed), and horizontal winds ( $\left.\mathrm{m} \mathrm{s}^{-1}\right)$ at 0000 UTC (a) 10 Jun and (b) 12 Jun 2000. Contour intervals are $30 \mathrm{gpm}$ for geopotential height and $3^{\circ} \mathrm{C}$ for temperature, respectively, and full (half) barbs represent $5(2.5) \mathrm{m} \mathrm{s}^{-1}$ for winds. Thick dashed (dotted) lines indicate the trough (ridge).

the Bashi Channel and brought cold air of $18^{\circ}-22^{\circ} \mathrm{C}$ well into southern China (see also section 1).

When the blocking pattern developed, similar amplification of the ridge-trough system also took place in the lower troposphere, as shown in Fig. 6 for $700 \mathrm{hPa}$ as an example. During 10-12 June, geopotential height values rose over central China and a southwardextending ridge formed near $110^{\circ} \mathrm{E}$ (Figs. 6a,b) as a hydrostatic response to the northerly cold air advection (CAA) and the large-scale confluence aloft (cf. Figs. $4 \mathrm{~b}, \mathrm{c}, 5 \mathrm{~b}, \mathrm{c})$. On 10 June (Fig. 6a), the northeasterly flow coincided with cold air $\left(<6^{\circ} \mathrm{C}\right)$ just behind the mei-yu front, over regions including the Sichuan area (cf. Fig. $1 b$ ), and produced strong shear with the prefrontal southwesterly flow along the front. The $700-\mathrm{hPa}$ high also reached peak intensity (3180 gpm) on 12 June, when the postfrontal flow strengthened to $10-13 \mathrm{~m} \mathrm{~s}^{-1}$ and continued to push the front southward (Fig. 6b). The overall evolution at $850 \mathrm{hPa}$ was similar to the conditions at $700 \mathrm{hPa}$, but it is not shown here.

\section{d. Vertical cross-sectional analyses}

Figure 7 presents the vertical cross sections along line $\mathrm{A}-\mathrm{B}$, from $45^{\circ} \mathrm{N}, 110^{\circ} \mathrm{E}$ to $20^{\circ} \mathrm{N}, 118.3^{\circ} \mathrm{E}$ with a northnorthwest-south-southeast alignment (cf. Fig. 4a). On 8 June, the frontal zone based on $\theta$ distribution was relatively narrow at low levels but much wider with a weaker $\theta$ gradient (flatter isentropes) at $700-500 \mathrm{hPa}$ (Fig. 7a), in agreement with Figs. 4-6. South of the front, $\theta$ values were higher than those to the north, by
3-5 K at low levels and as much as $20 \mathrm{~K}$ near $400 \mathrm{hPa}$, consistent with the appearance of the ULJ near $36^{\circ} \mathrm{N}$ based on the thermal wind relationship (cf. Fig. 5a). As the 500-hPa block formed, northerly flow existed behind and within the frontal zone throughout the troposphere on the section plane, and induced confluence and convergence within the zone, most evidently at low-midlevels (Fig. 7b).

On 10 June, in response to the confluence/convergence, the frontal $\theta$ gradient increased and the midlevel frontal zone narrowed (Fig. 7c). Associated with an increase in postfrontal east-northeasterlies, the crossfrontal horizontal wind shear below $500 \mathrm{hPa}$ also strengthened, consistent with the response to low-level frontogenesis based on semigeostrophic theory (e.g., Shapiro and Keyser 1990; Bluestein 1993, his section 2.5). Strong confluence/convergence, meanwhile, continued to occur within the frontal zone below $350 \mathrm{hPa}$ (Fig. 7d). On 12 June, the leading edge of the front had advanced to $23^{\circ} \mathrm{N}$ near the surface, and the low-level wind shear continued to intensify but the frontal convergence had started to weaken (Figs. 7e,f). The frontal structure in Fig. 7, especially after 8 June, was similar to those constructed by Chen et al. (1989) and Chen and Hui (1990).

\section{e. Satellite imagery and clouds}

The GMS-5 IR imagery shows that on 8 June only scattered convection existed behind the surface mei-yu front except in southwestern China (Fig. 8a). By 
SECT AB VN/PT 2000 Jun $800 Z$

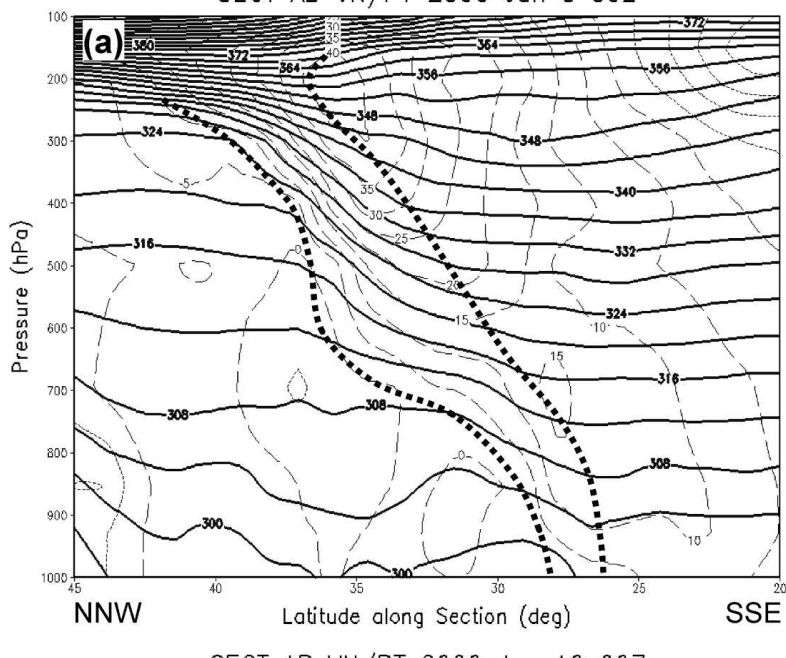

SECT AB VN/PT 2000 Jun $1000 Z$

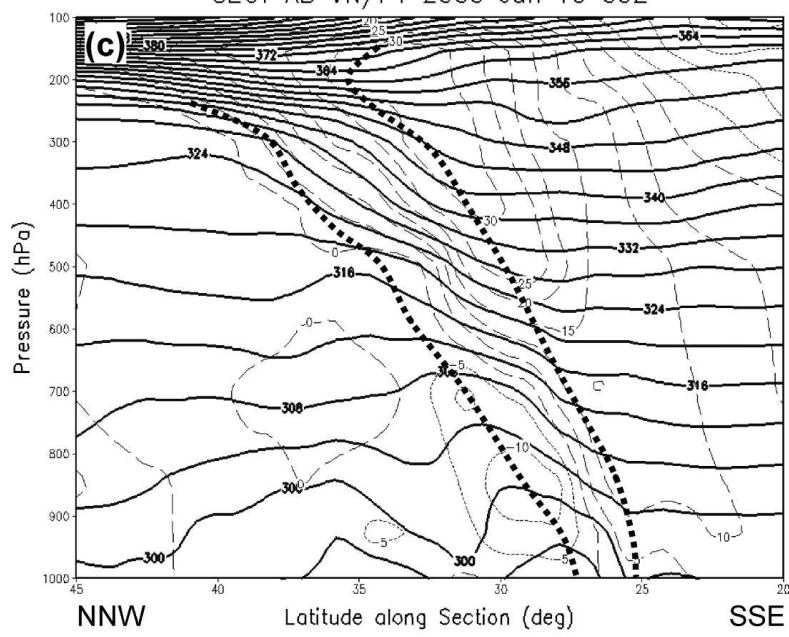

SECT AB VN/PT 2000 Jun $1200 Z$

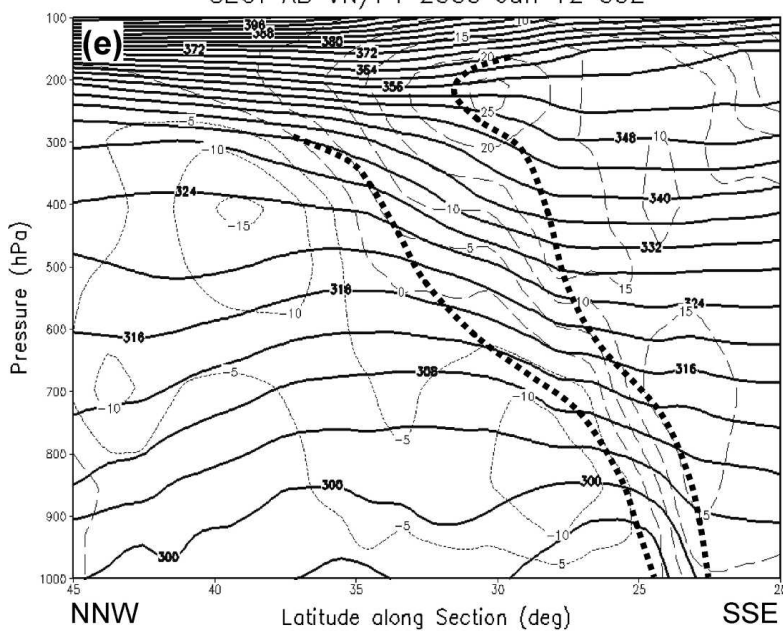

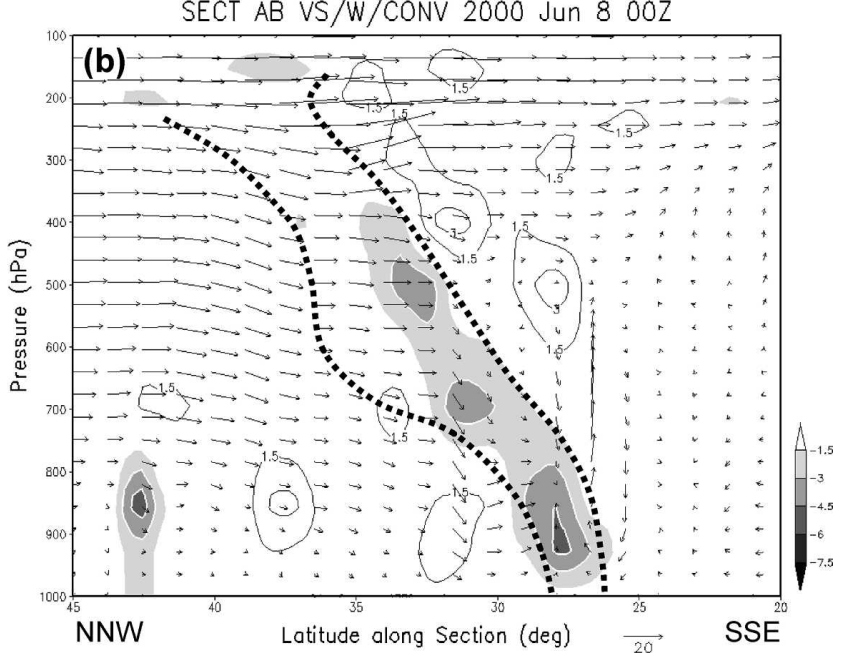

SECT AB VS/W/CONV 2000 Jun $1000 Z$

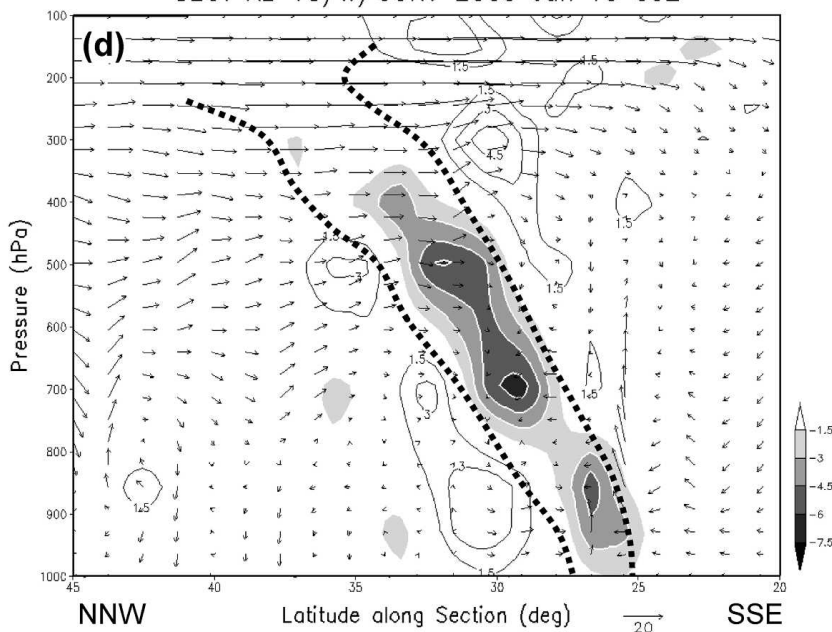

SECT AB VS/W/CONV 2000 Jun $1200 Z$

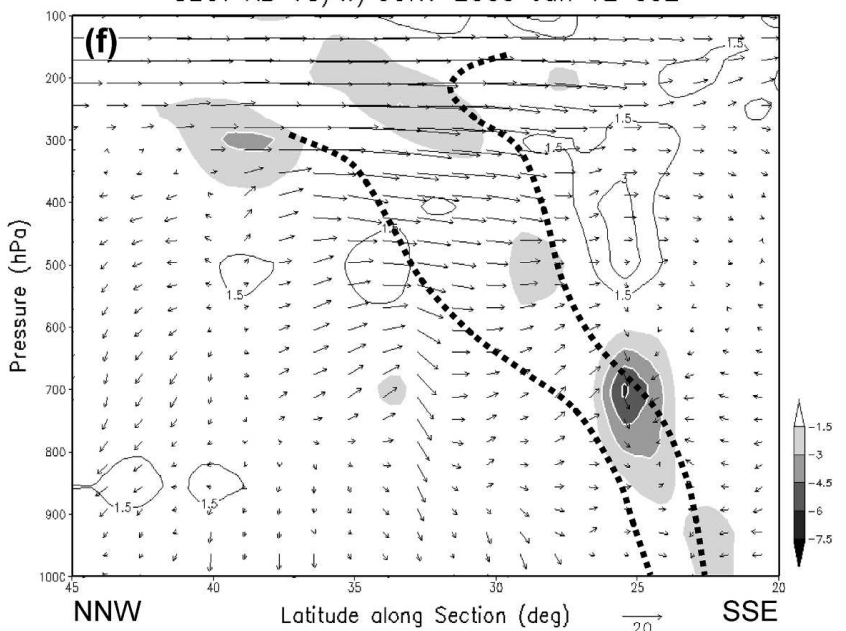

FIG. 7. Vertical cross section of (a) potential temperature $(\theta, \mathrm{K}$, solid) and horizontal wind components normal to the section plane $\left[\mathrm{m} \mathrm{s}^{-1}\right.$; dashed (dotted) for positive (negative) values, defined as into (out of) the plane], and (b) wind vectors $\left(\mathrm{m} \mathrm{s}^{-1}\right.$ and Pa s$^{-1}$ ) on the section plane and divergence $\left[10^{-5} \mathrm{~s}^{-1}\right.$; contours (shading) for divergence (convergence)] along line $\mathrm{A}-\mathrm{B}$ (from $45^{\circ} \mathrm{N}, 110^{\circ} \mathrm{E}$ to $20^{\circ} \mathrm{N}, 118.3^{\circ} \mathrm{E}$; marked in Fig. 4a) at 0000 UTC 8 Jun 2000. Contour intervals are $4 \mathrm{~K}$ for $\theta$ and $5 \mathrm{~m} \mathrm{~s}^{-1}$ for winds in (a) and $1.5 \times 10^{-5}$ $\mathrm{s}^{-1}$ (zero line omitted) for divergence in (b). A vector length of $20 \mathrm{~m} \mathrm{~s}^{-1}$ for horizontal wind is indicated at the bottom, and a length of $100 \mathrm{hPa}$ is equivalent to $1 \mathrm{~Pa} \mathrm{~s}^{-1}$ for vertical velocity in (b). Thick dotted lines mark the frontal zone based on the $\theta$ distribution. (c), (d) and (e), (f) Same as (a), (b), but for 0000 UTC 10 Jun and 12 Jun 2000, respectively. 

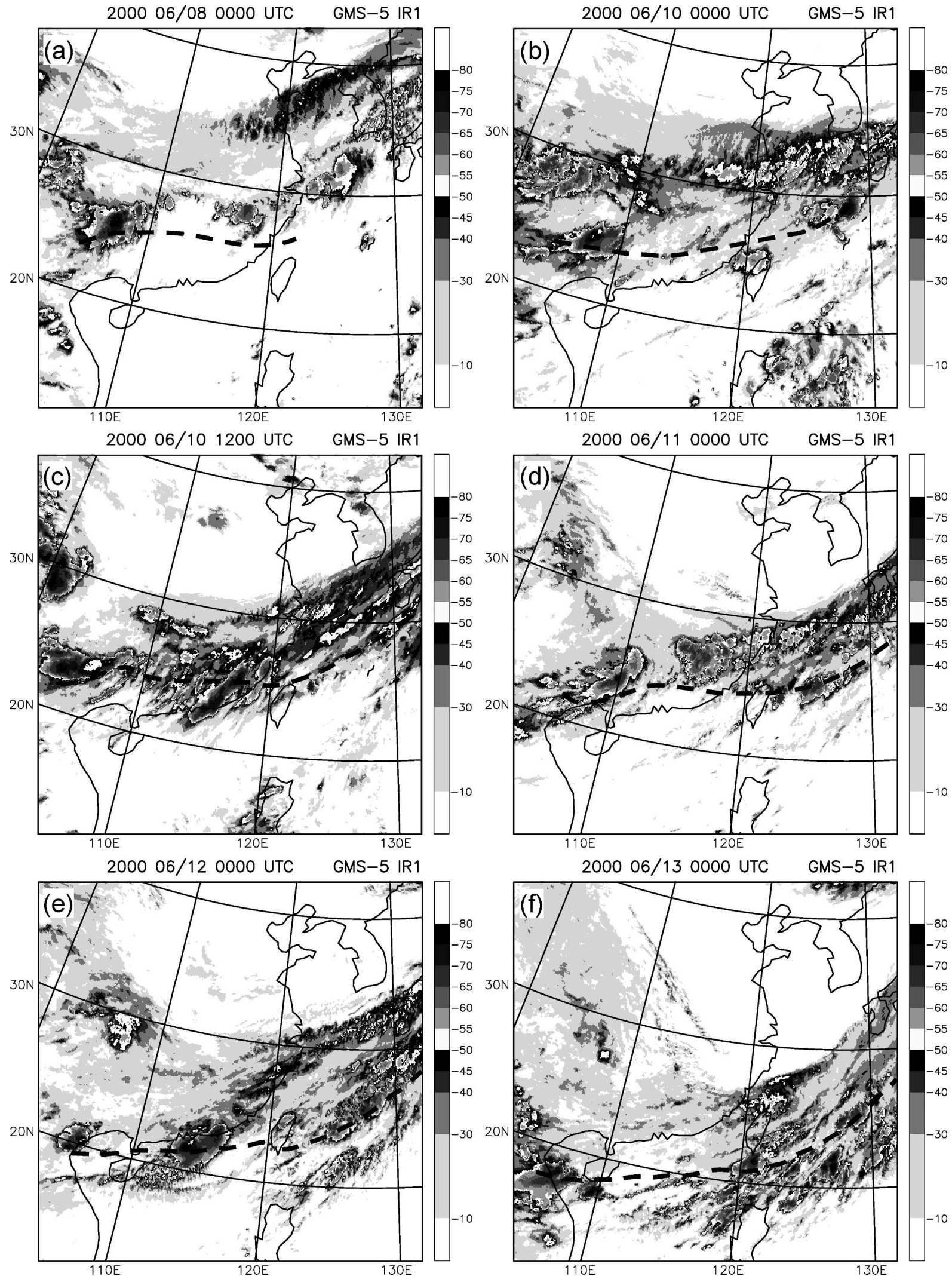

FIG. 8. GMS-5 satellite IR blackbody brightness temperature $\left({ }^{\circ} \mathrm{C}\right)$ at (a) 0000 UTC 8 Jun, (b) 0000 UTC 10 Jun, (c) 1200 UTC 10 Jun, (d) 0000 UTC 11 Jun, (e) 0000 UTC 12 Jun, and (f) 0000 UTC 13 Jun 2000. Thick dashed lines indicate surface frontal position. 
0000 UTC (0800 LST) 10 June, widespread convection broke out and gradually organized into a banded shape mostly on the cold side of the front after 1200 UTC (2000 LST; Figs. 8b,c). Thus, the frontal cloud band coincided with lower surface temperatures (cf. Fig. 1b), which were caused likely by a combination of cold advection, evaporative cooling from precipitation, and a reduction in daytime solar heating from cloud coverage. Over the cloud-free area north of the cloud band, in contrast, air temperatures were significantly higher and reached $26^{\circ}-30^{\circ} \mathrm{C}$ (cf. Fig. 1b).

By 0000 UTC 11 June (Fig. 8d), more deep convection had broken out over southern China behind the front, while central and northern China continued to have little cloud under the control of the block and northerly flow (cf. Figs. 4b,c, 6b). Conditions on 12 June remained similar as the front moved offshore (Fig. 8e). At 0000 UTC 13 June, the convection was inactive over southern China but temperatures there were only $18^{\circ}-$ $21^{\circ} \mathrm{C}$ (Figs. 8f, 1c), a clear indication for the existence of CAA at low levels.

\section{Frontogenetical function and processes}

Using the method described in section $2 b$, the $2 \mathrm{D}$ frontogenetical function of Ninomiya (1984) was calculated. The interpretation of the pattern of $F$ in relation to the frontal thermal gradient pattern follows the principle below: intensification (weakening) of the front or frontogenesis (frontolysis) occurs when the $F$ pattern is in phase (out of phase) with the thermal gradient, and frontal propagation occurs when the two patterns differ by approximately $90^{\circ}$ (in quadrature). While the movement of the front is the sum of frontal propagation (through air parcels) and transport (by air parcels), the frontogenetical function, being a parcel-relative quantity, reveals information about propagation but not transport, so one should be aware of this. The calculation of Eqs. (1)-(6) is also a purely kinematic examination, which presents additional limitations in certain dynamical aspects. As discussed by Carlson (1991, his section 13.4) and Bluestein (1993, his section 2.5), the development of transverse circulation and an upperlevel front in response to surface frontogenesis [i.e., the adjustment process once low-level geostrophy breaks down because of an increase in the thermal gradient (also Shapiro and Keyser 1990)] cannot be addressed explicitly by the kinematic approach. Thus, one needs to be cautious in the interpretation of frontogenetical function results because of the above limitations, especially in frontal movement and evolution.

In this section, we examine only the results at $925 \mathrm{hPa}$ to reduce the influence of topography (cf. Fig. 2), al- though 1000-hPa results were similar. Also, because the tilting term (FG4) was much smaller than the remaining terms because of the small horizontal gradient of $\omega$ near the surface, its result will not be shown. Based on temperature gradient (and horizontal winds wherever consistent) in the ECMWF analysis, the mei-yu frontal position at $925 \mathrm{hPa}$ was determined as shown in Fig. 9. On isobaric surfaces, temperature gradients are equivalent to $\theta$ gradients, critical for the identification of true frontal position and the subsequent examination on frontal propagation based on the phase difference between the front and frontogenetical forcing terms (e.g., Sanders 1999a; Schultz 2005, 2007). In Fig. 9, the thermal gradient of the $925-\mathrm{hPa}$ front increased from 8 June to reach a maximum at 1200 UTC 10 June, then remained quite strong until after 12 June, in close agreement with Figs. 1 and 7.

\section{a. Total frontogenetical function}

The frontogenetical function $F$, magnitude of $\theta$ gradients, and frontal positions during 8-13 June 2000 are shown in Fig. 10. On 8 June (Fig. 10a), the frontal $\theta$ gradient was still weak, and the frontogenetical function $F$, although not well organized in shape, was positive along the front $\left[10^{-10} \mathrm{~K} \mathrm{~m}^{-1} \mathrm{~s}^{-1}=0.864 \mathrm{~K}(100\right.$ $\mathrm{km})^{-1}$ day $^{-1}$ ]. At 0000 UTC 10 June (Fig. 10b), the frontal $\theta$ gradient increased to $2-3 \mathrm{~K}(100 \mathrm{~km})^{-1}$ and the area of positive $F$ had taken a banded shape and was collocated with the $925-\mathrm{hPa}$ front (i.e., slightly ahead of the maximum $\theta$ gradient). Over the northern Taiwan Strait, positive $F$ also appeared, as both prefrontal and postfrontal flows tended to be stronger over the ocean (cf. Figs. 1b, 9b). At 1200 UTC 10 June (Fig. $10 \mathrm{c})$, the $\theta$ gradient reached a peak of $4.5 \mathrm{~K}(100 \mathrm{~km})^{-1}$ with a total cross-frontal difference of 8-12 K (cf. Fig. 9c). The region of $F>0$ remained slightly ahead of the frontal zone, and the largest value of $16 \times 10^{-10}$ $\mathrm{K} \mathrm{m}^{-1} \mathrm{~s}^{-1}$ during the case period appeared near $23^{\circ} \mathrm{N}$, $108^{\circ} \mathrm{E}$. The positive $F$ ahead of the mei-yu front indicated southward propagation and was consistent with observations revealed by comparing fronts at successive times in Fig. 9, although the frontal movement was also, and often largely, dictated by the large-scale postfrontal cold air (Smith and Reeder 1988; Bluestein 1993, p. 259). At 0000 UTC 11 June, the front west of $110^{\circ} \mathrm{E}$ moved rapidly southward and $F>0$ still existed ahead of the front (Fig. 10d). On the other hand, negative $F$ appeared about $150-300 \mathrm{~km}$ behind the front.

East of about $113^{\circ} \mathrm{E}$, the frontal thermal contrast was maintained at 0000 UTC 12 June as the front nearly moved offshore (Fig. 10e). The positive $F$ ahead of the frontal zone remained clear as did the negative $F$, although weaker, immediately behind, consistent with 
$925 \mathrm{hPa} \mathrm{Z/UV/T} 2000$ Jun $800 \mathrm{Z}$

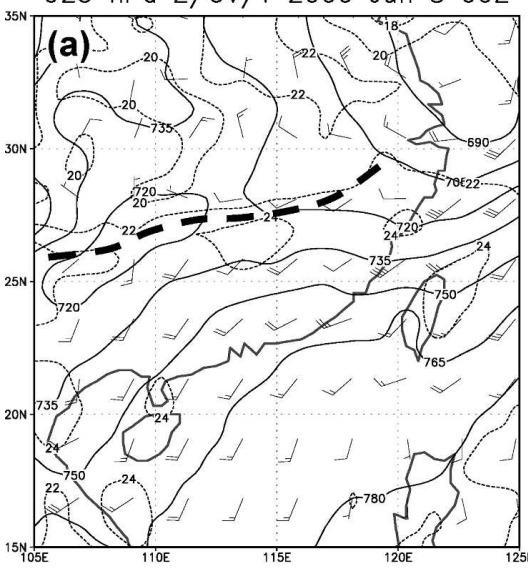

$925 \mathrm{hPa} \mathrm{Z} / \mathrm{UV} / \mathrm{T} 2000$ Jun $1100 \mathrm{O}$

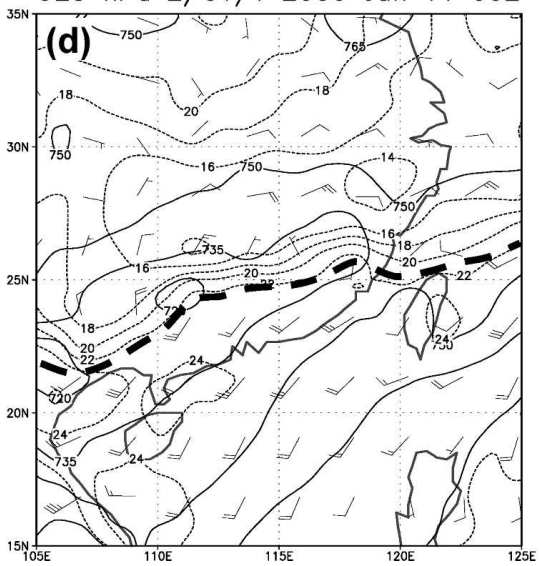

$925 \mathrm{hPa}$ Z/UV/T 2000 Jun 10 00Z

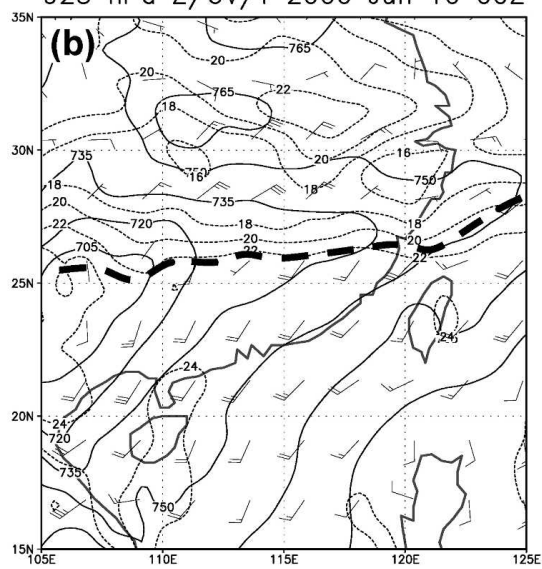

$925 \mathrm{hPa} \mathrm{Z} / \mathrm{UV} / \mathrm{T} 2000$ Jun 12 00Z

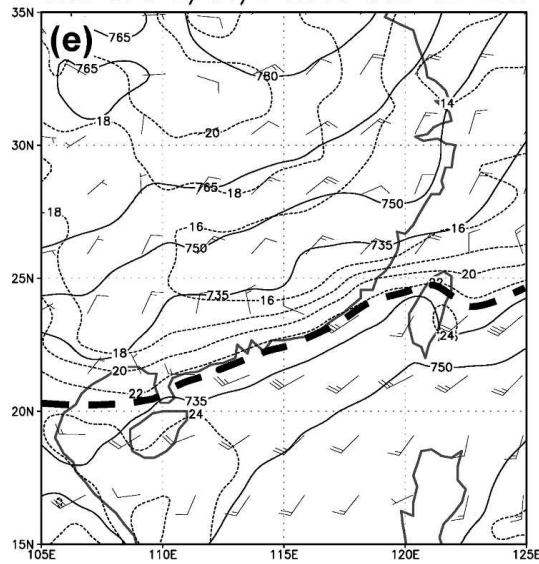

$925 \mathrm{hPa}$ Z/UV/T 2000 Jun $1012 \mathrm{Z}$

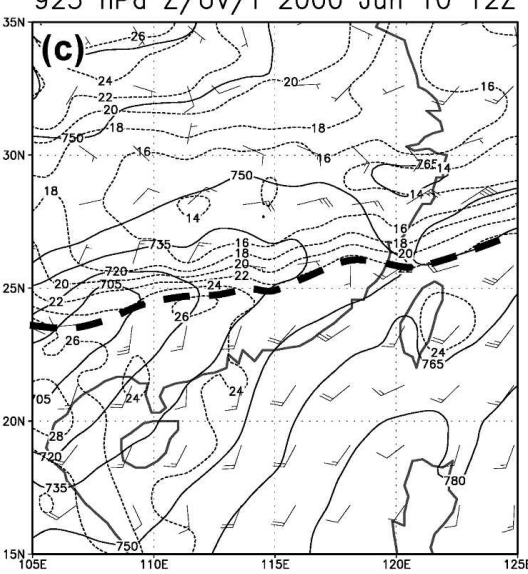

$925 \mathrm{hPa} \mathrm{Z/UV/T} 2000$ Jun 13 o0Z

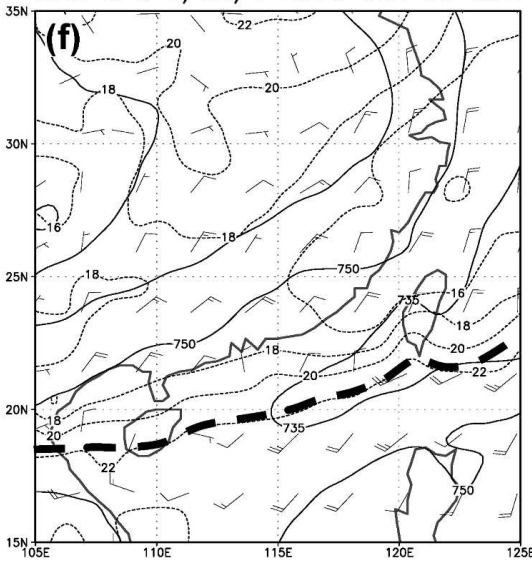

FIG. 9. Same as Fig. 6, but for $925 \mathrm{hPa}$ over the domain of $15^{\circ}-35^{\circ} \mathrm{N}, 105^{\circ}-125^{\circ} \mathrm{E}$ at (a) $0000 \mathrm{UTC} 8 \mathrm{Jun}$, (b) $0000 \mathrm{UTC} 10 \mathrm{Jun}$, (c) 1200 UTC 10 Jun, (d) 0000 UTC 11 Jun, (e) 0000 UTC 12 Jun, and (f) 0000 UTC 13 Jun 2000. Contour intervals are 15 gpm for geopotential height and $2{ }^{\circ} \mathrm{C}$ for temperature, respectively. Thick dashed lines indicate the position of the 925-hPa mei-yu front based on temperature gradient and winds.

the continuous southward frontal movement (cf. Figs. $9 \mathrm{~d}, \mathrm{e})$. At 0000 UTC 13 June after the front entered the South China Sea, $F<0$ appeared along most of the frontal zone and the associated $\theta$ gradient weakened (frontolysis) as expected (Fig. 10f). At this time, however, $F>0$ still existed ahead of the front.

\section{b. Frontogenesis due to convergence}

During 8-11 June, frontogenesis from pure horizontal convergence (FG2) in southern China increased significantly to reach $6-12 \times 10^{-10} \mathrm{~K} \mathrm{~m}^{-1} \mathrm{~s}^{-1}$ (Figs. 11ad). Large positive FG2 values in general were collocated with the frontal zone (along maximum $\theta$ gradient), in agreement with Fig. 7, and thus contributed toward the intensification or maintenance of the front. On 12 June, the convergence effect west of $114^{\circ} \mathrm{E}$ weakened but was still positive, even after the front entered the South China Sea (Figs. 11e,f). Throughout the period, small negative FG2 values existed to the north of the frontal zone, also consistent with the weak low-level divergence seen in Figs. 7b,d. During 10-12 June, convergent frontogenesis also tended to be stronger over the northern Taiwan Strait (Figs. 11c-e).

\section{c. Frontogenesis due to deformation}

The frontogenetic forcing from deformation (FG3) was weak on 8 June, but regions of positive values formed into a band structure along the frontal zone by 10 June (Figs. 12a,b). From 8 to 11 June, values of FG3 also grew larger (to 8-12 $\times 10^{-10} \mathrm{~K} \mathrm{~m}^{-1} \mathrm{~s}^{-1}$ ), particularly west of $115^{\circ} \mathrm{E}$ where flow confluence along the frontal zone was significant (cf. Fig. 9). On 11 and 12 June (Figs. 12d,e) over land, the largest FG3 values were somewhat ahead of the zone of the maximum $\theta$ gradient, thus contributing to not only frontogenesis but likely also the forward propagation of the mei-yu 
FG TOT 2000 Jun $800 Z$

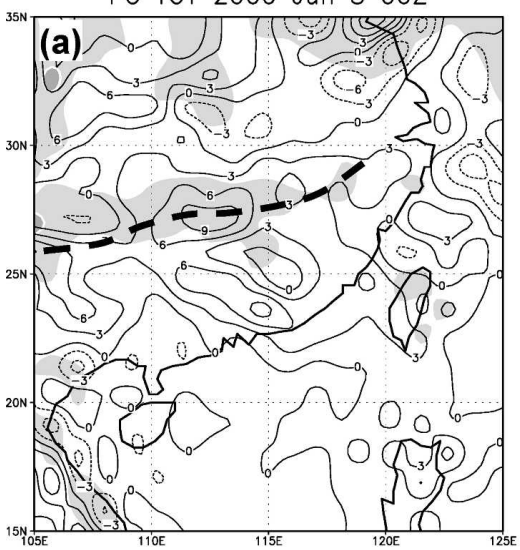

FG TOT 2000 Jun 11 00Z

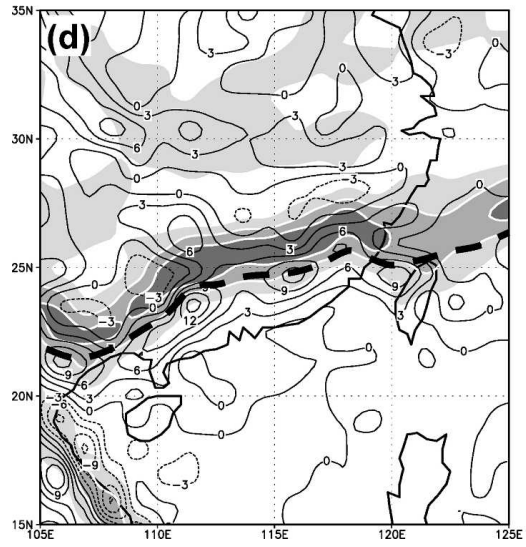

FG TOT 2000 Jun 10 00Z

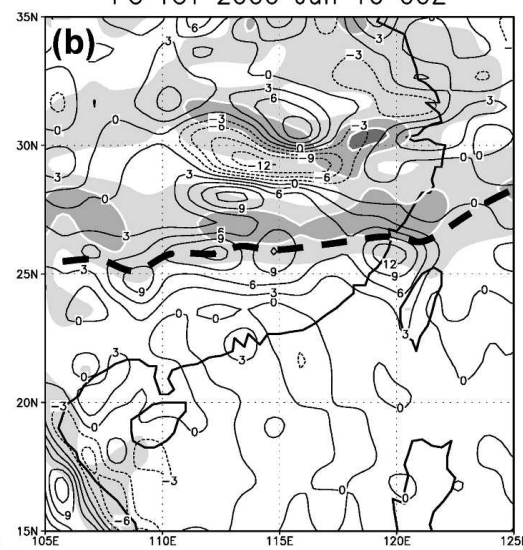

FG TOT 2000 Jun 12 o0Z

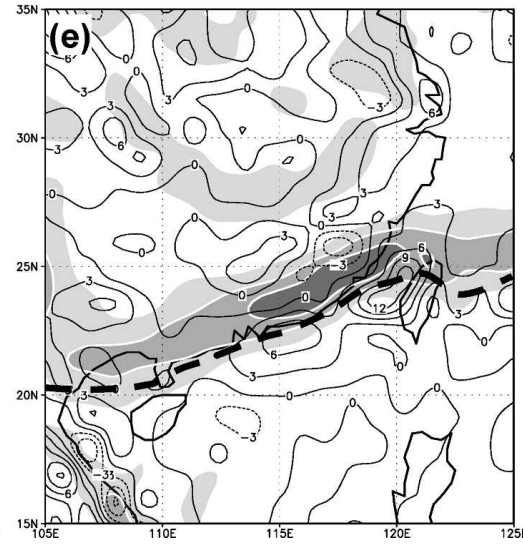

FG TOT 2000 Jun $1012 Z$

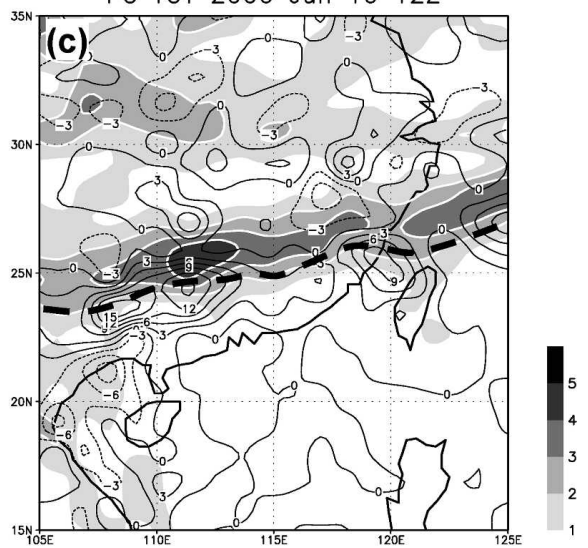

FG TOT 2000 Jun 13 00Z

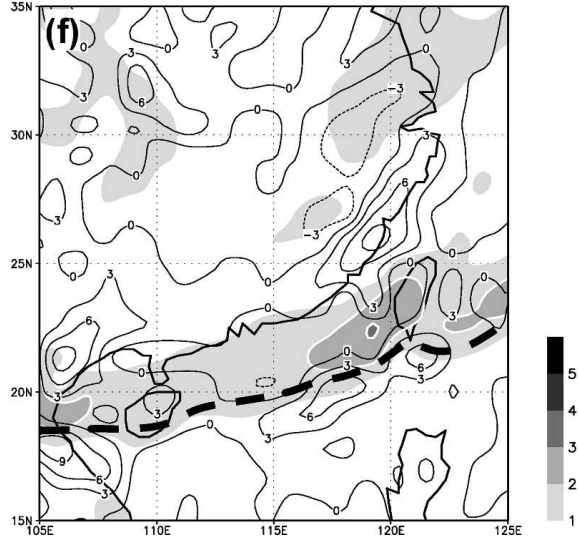

FIG. 10. The $925-\mathrm{hPa}$ frontogenetical function $\left(F ; 10^{-10} \mathrm{~K} \mathrm{~m}^{-1} \mathrm{~s}^{-1}\right.$; contours) at (a) 0000 UTC 8 Jun, (b) 0000 UTC 10 Jun, (c) 1200 UTC 10 Jun, (d) 0000 UTC 11 Jun, (e) 0000 UTC 12 Jun, and (f) 0000 UTC 13 Jun 2000. Contour intervals are $3 \times 10^{-10} \mathrm{~K} \mathrm{~m}^{-1} \mathrm{~s}^{-1}$, and solid (dashed) lines indicate positive (negative) values. Shadings are magnitudes of the $\theta$ gradient [K $\left.(100 \mathrm{~km})^{-1}\right]$ with a scale shown at the lower rhs of (c), (f). Thick dashed lines mark the position of the 925-hPa front.

front. Near the northern Taiwan Strait, FG3 $>0$ also existed and contributed positively, with a maximum at 1200 UTC 10 June (Fig. 12c). At 0000 UTC 12 June (Fig. 12e), the forcing from FG3 weakened both west of $113^{\circ} \mathrm{E}$ and near the Taiwan Strait, but intensified along the front in between. After the front moved offshore, FG3 values were reduced but still mostly positive along the front, while the overall shape of distribution became less compact. Similar to convergence, the contribution from FG3 to frontogenesis also agreed well with the low-level confluence seen in vertical cross sections (Fig. 7).

\section{d. Frontogenesis due to diabatic effects}

Effects of diabatic processes on frontogenetical function (FG1) are discussed in this subsection. On 8 June (Fig. 13a), the FG1 pattern near the mei-yu front was roughly in phase with the $\theta$ gradient with a distribution quite similar to that of $F$ (cf. Fig. 10a), suggesting that the front was maintained primarily through diabatic ef- fects at early stages. Along the frontal zone, regions with FG1 > 0 gradually diminished through 0000 UTC 10 June (Fig. 13b) and large negative FG1 values appeared over the next $24 \mathrm{~h}$ with a peak value of $-18 \times$ $10^{-10} \mathrm{~K} \mathrm{~m}^{-1} \mathrm{~s}^{-1}$, leading to strong frontolysis (Figs. $13 c, d)$. During this period, diabatic effects were also strongly frontolytic east of about $118^{\circ} \mathrm{E}$ over the ocean. On the other hand, positive FG1 gradually appeared ahead of the front over the coastal area of southern China on 11 June (Fig. 13d), and both bands of FG1 < 0 along the frontal zone and FG1 $>0$ farther south remained evident through 13 June, even after the front moved offshore and weakened (Figs. 13e,f).

Diabatic effects on frontogenesis are related to the heating rate $(d \theta / d t)$, which is shown in Fig. 14. At 0000 UTC (0800 LST) 8 June (Fig. 8a), heating occurred south of $27^{\circ} \mathrm{N}$, over the warm side of the $925-\mathrm{hPa}$ front, after local sunrise under clear-sky conditions (cf. Figs. 9a, 14a), and diabatic processes acted to maintain the front (Fig. 13a). Segal et al. (1993) suggested that such 
FG CONV 2000 Jun $800 Z$

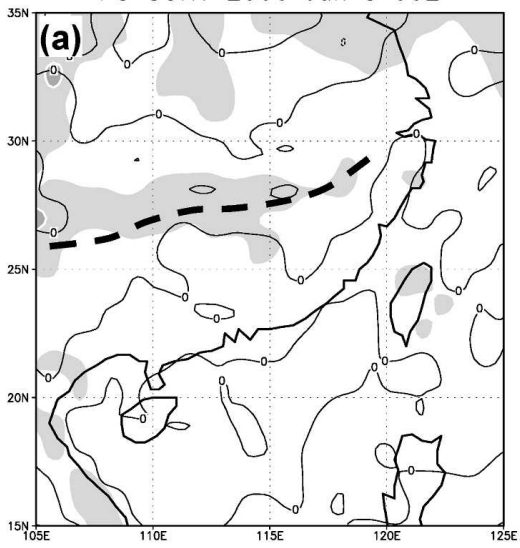

FG CONV 2000 Jun $1100 Z$

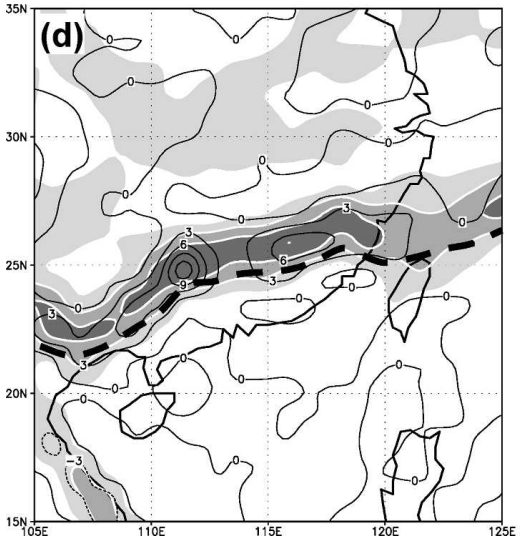

FG CONV 2000 Jun $1000 Z$

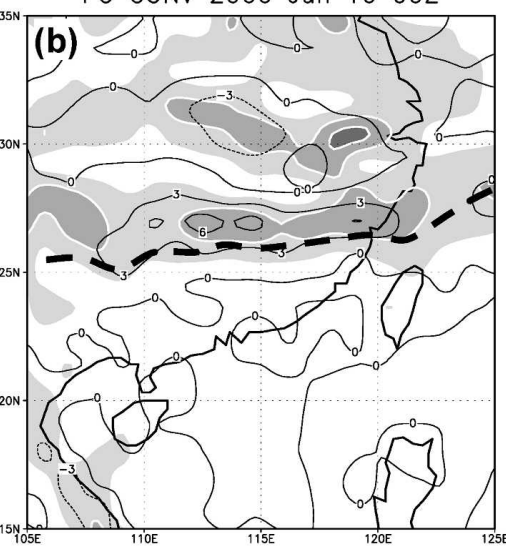

FG CONV 2000 Jun $1200 Z$

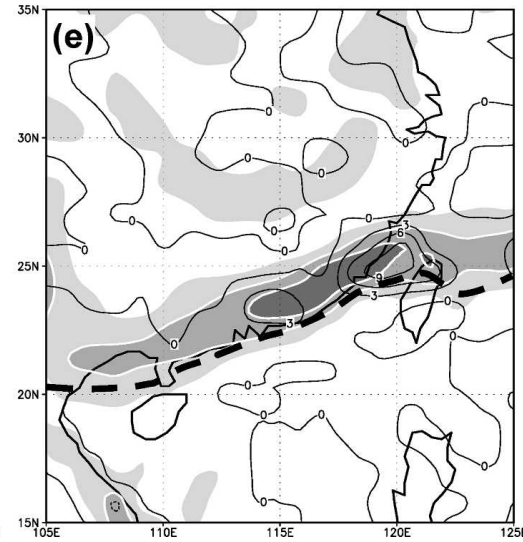

FG CONV 2000 Jun $1012 Z$

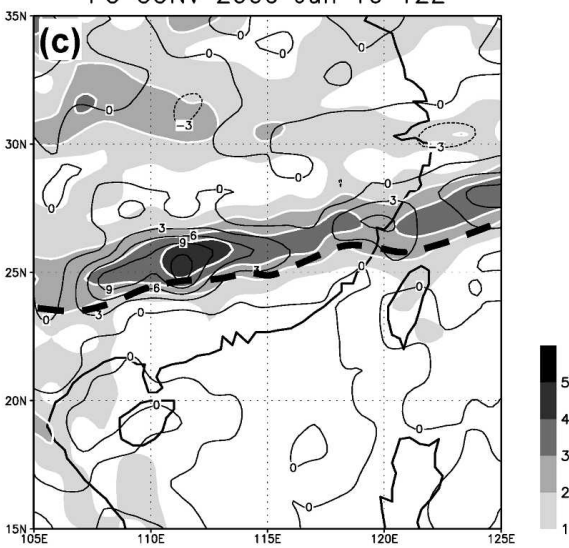

FG CONV 2000 Jun 13 00Z

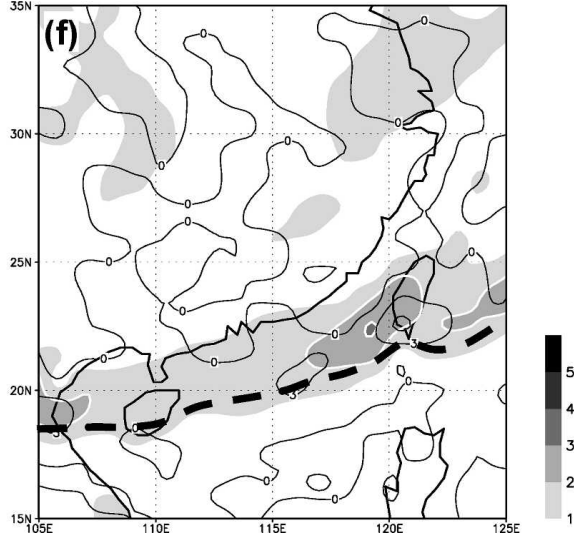

FIG. 11. Same as Fig. 10, but for frontogenesis $\left(10^{-10} \mathrm{~K} \mathrm{~m}^{-1} \mathrm{~s}^{-1}\right)$ from horizontal convergence (FG2).

a configuration in cloud cover can lead to differential heating and sensible heat transfer across the front during the day in summer, thereby promoting frontogenesis (also Sanders 1999b).

Between 1200 UTC 10 and 0000 UTC 12 June, after the front intensified, diabatic effects along the frontal zone became strongly frontolytic (Figs. 13c-e), which was due to a combination of significant cooling (up to $-1.4 \mathrm{~K} \mathrm{~h}^{-1}$ ) immediately ahead of and (usually weaker) warming just behind the maximum $\theta$ gradient (Figs. 14c-e). The cloud band during this period was behind the surface front, but since the $925-\mathrm{hPa}$ front was also north of the surface front, the more active convection appeared nearly along the $925-\mathrm{hPa}$ front (cf. Figs. 8c-e). Because thermal advection is adiabatic and radiation/surface fluxes should contribute toward warming at $0800 \mathrm{LST}$, the persistent cooling (generally stronger at $1000 \mathrm{hPa}$ but not shown) must be due to evaporation of frontal precipitation. This type of cooling, as shown by Schultz and Trapp (2003) and reviewed by Schultz (2005), could also occur aloft and alter the frontal structure. The warming at the back side of the frontal zone, often under less cloud cover (cf. Fig. 8) was most likely a result of stronger sensible heat transfer into postfrontal cold air from the surface, aided by stronger solar heating (at 0000 UTC; e.g., Koch et al. 1995). Daytime heating apparently also occurred south of the front and was particularly strong along the coast of the Indochina Peninsula under cloud-free skies (Figs. $8,14)$. Thus, with cooling along the $925-\mathrm{hPa}$ front and warming farther away at both sides, diabatic effects caused frontolysis within the frontal zone and FG1 $>0$ ahead of the front (Fig. 13).

\section{e. Overall contribution from different processes}

From Figs. 10-13, different processes were found to play different roles toward the intensity and/or movement of the present mei-yu front at different stages of the blocking event. The alongfront averages of these terms and magnitude of the $\theta$ gradient over $108^{\circ}-120^{\circ} \mathrm{E}$ are shown in Fig. 15 from $5.625^{\circ}$ south to $7.875^{\circ}$ north of the 925-hPa front, which was taken to be the grid point closest to the actual front along each longitude in ECMWF data (cf. Fig. 9). Note that the imperfect sum- 

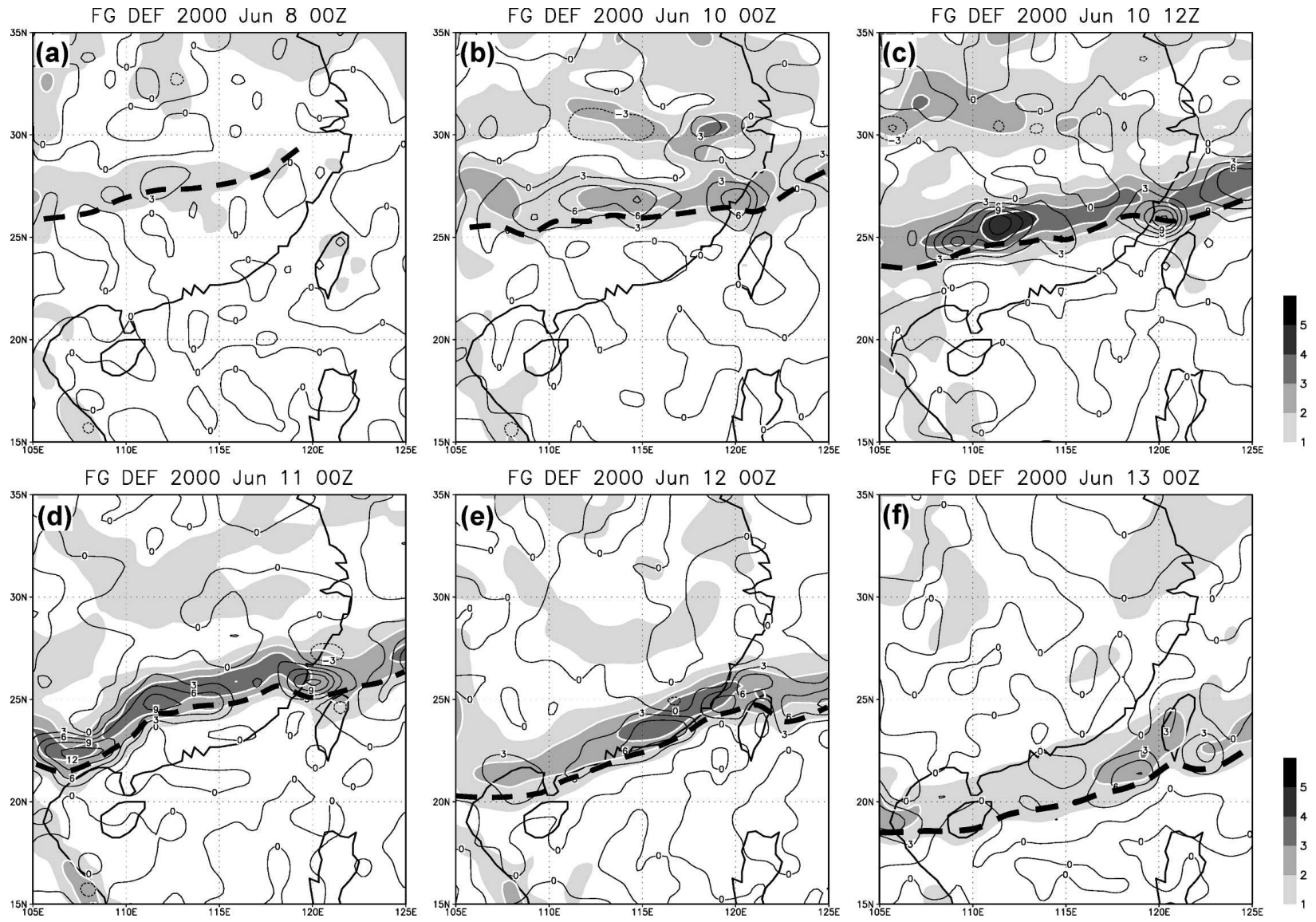

FIG. 12. Same as Fig. 10, but for frontogenesis $\left(10^{-10} \mathrm{~K} \mathrm{~m}^{-1} \mathrm{~s}^{-1}\right)$ from deformation (FG3).

mations are evident in Fig. 15 because $F$ in Eq. (1) was calculated from the Lagrangian derivatives, not the sum of the forcings (section $2 \mathrm{~b}$ ), and so there is a residual due to computational error and also due to the neglect of the tilting term (FG4). During the formation stage (Fig. 15a), all three terms of FG1 (diabatic processes), FG2 (convergence), and FG3 (deformation) were in phase with the frontal zone, with the front mainly maintained through diabatic effects. During the intensification stage (9-11 June), the frontal $\theta$ gradient strengthened and maximized about $120 \mathrm{~km}$ north of the front (Figs. 15b-d). Diabatic effects became strongly frontolytic, while convergence frontogenesis nearly collocated with the frontal zone. The deformation, while also frontogenetic with roughly the same contribution as convergence, had a tendency to peak slightly forward. When the three terms are added, the total $F$ was mostly positive near the front, so that the combined frontogenesis from FG2 and FG3 overcame the frontolysis of FG1 (Figs. 15b-d). The resultant maximum value of total $F$ appeared ahead of the frontal zone because the peaks of FG2 and FG3 were located more forward compared with FG1 (Figs. 15c,d), except at 0000 UTC 10 June when both FG1 and $F$ had peaks along the front (Fig. 15b). Thus, the patterns of all three terms, especially deformation, also helped this mei-yu front to propagate south. After the block matured, basic patterns of $F$ and FG1-FG3 remained similar but their magnitudes gradually decreased (Figs. 15e,f). The front entered the South China Sea by 13 June, and the area of negative FG1, although weakening, appeared wider than earlier times (Fig. 15f). Because the effects of FG2 and FG3 were also reduced, the frontal $\theta$ gradient weakened mainly due to the continuous sensible heat flux over warmer water into the postfrontal cold air (cf. Figs. 9f, 14f), in agreement with Trier et al. (1990).

The change in frontal strength (in terms of $\left|\nabla_{H} \theta\right|$, curve GT) can be easily observed in Fig. 15 in a frontrelative (i.e., quasi-Lagrangian) space. The earthrelative (Eulerian) frontal motion exists when there is a phase difference between the local tendency of $\left|\nabla_{H} \theta\right|$ and the frontal zone, and is related to the (parcel relative) propagation represented by $F$ and the transport by 
FG DIAB 2000 Jun $800 Z$

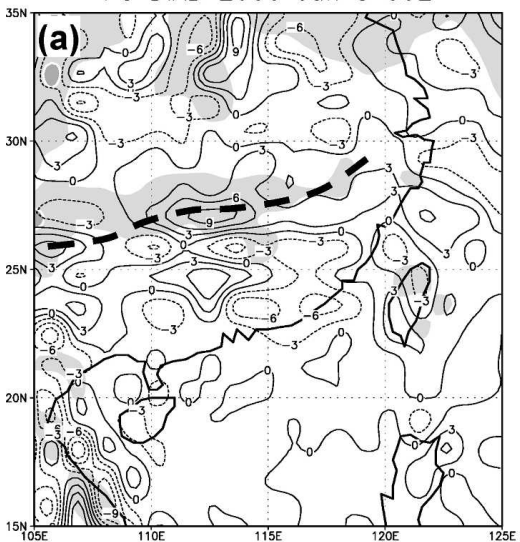

FG DIAB 2000 Jun 11 00Z

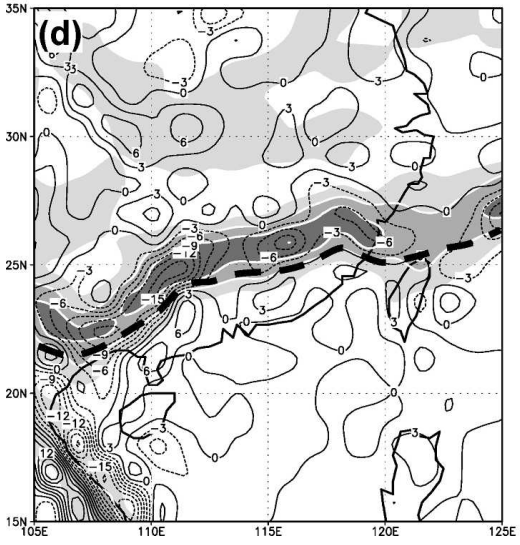

FG DIAB 2000 Jun 10 00Z

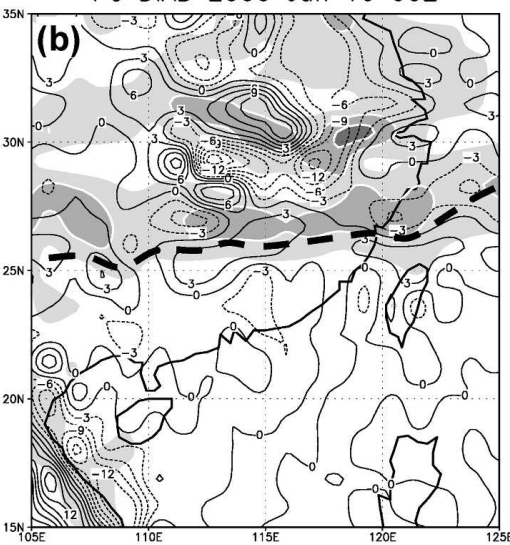

FG DIAB 2000 Jun $1200 Z$

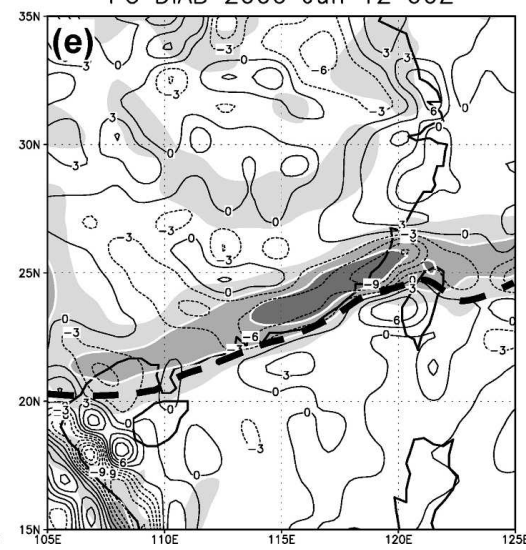

FG DIAB 2000 Jun $1012 Z$

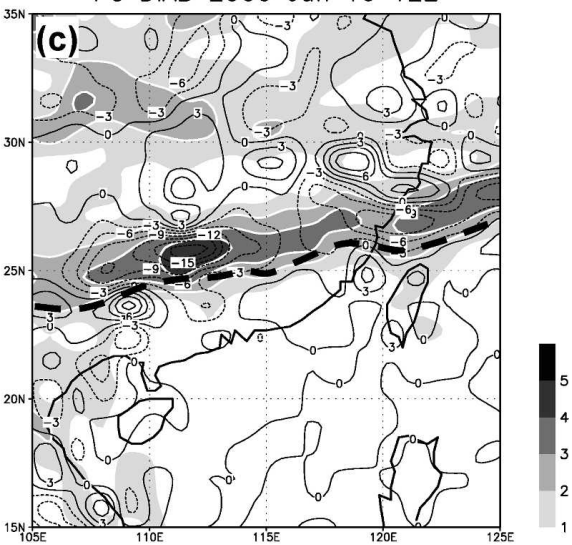

FG DIAB 2000 Jun 13 00Z

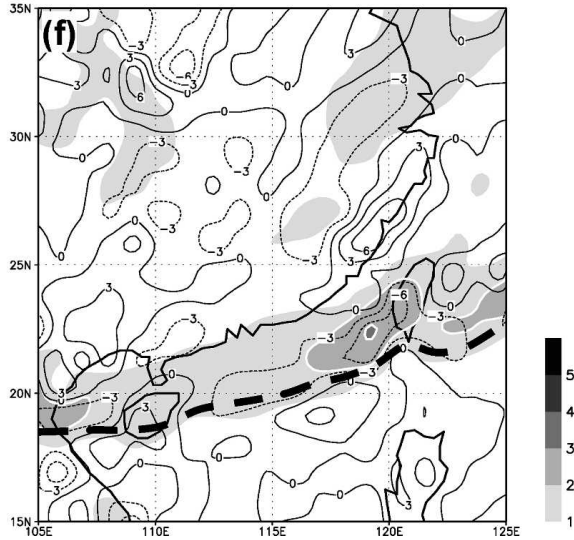

FIG. 13. Same as Fig. 10, but for frontogenesis $\left(10^{-10} \mathrm{~K} \mathrm{~m}^{-1} \mathrm{~s}^{-1}\right)$ from diabatic effects (FG1).

advection (omitting vertical motion) through applying Eq. (6) as

$$
\frac{\partial}{\partial t}\left|\boldsymbol{\nabla}_{H} \theta\right|=F-\mathbf{V} \cdot \boldsymbol{\nabla}_{H}\left|\boldsymbol{\nabla}_{H} \theta\right|
$$

The values of local tendency (LT) and horizontal advection $\left(-\mathbf{V} \cdot \nabla_{H}\left|\nabla_{H} \theta\right| ; \mathrm{ADV}\right)$ of the magnitude of the horizontal $\theta$ gradient in Eq. (7) are shown in Fig. 16, where the summations are exact. From 8 June to 0000 UTC 10 June, the total $F$ contributed toward a positive LT that was roughly in-phase with the frontal $\theta$ gradient, resulting in the intensification of the front (Figs. $16 a, b)$ as discussed. When the front grew stronger, the effect of ADV was negative near the front through 11 June, especially immediately ahead of and behind the zone of maximum $\theta$ gradient (Figs. 16b-d), obviously caused by the horizontal convergence and confluence (FG2 and FG3; cf. Figs. 15b-d). During this period, the total $F$, as described earlier, peaked ahead of the frontal zone and resulted in positive local tendency also slightly ahead of the front, and thus the forward propagation of the front was contributing toward its total southward movement. During 12-13 June (Figs. 16e,f), the advection term became positive (though small) ahead of and negative behind the front, indicating that the confluence/convergence along the front was weakening, consistent with Fig. 15, and that the postfrontal cold air advection was dominant at this time. The local tendency was roughly $90^{\circ}$ ahead of the front and reached its peak value on 12 June (Fig. 16e), also in agreement with the rapid southward movement of the $925-\mathrm{hPa}$ front during the period (Figs. 9d-f; Smith and Reeder 1988).

\section{Discussion}

\section{a. Blocking development and associated phenomena}

In section 3 , it was found that the mei-yu front over southern China was initially shallow and its baroclinity relatively weak (Figs. 1a, 4a, 7a). Not yet very strong, the ridge over Mongolia appeared above $700 \mathrm{hPa}$ and was associated with large-scale confluence on 8 June. The ridge-trough system exhibited a westward tilt with 
HEAT RATE 2000 Jun 8 00Z

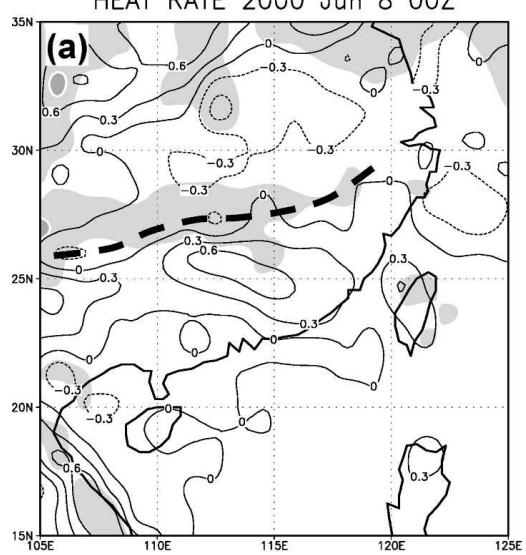

HEAT RATE 2000 Jun 11 00Z

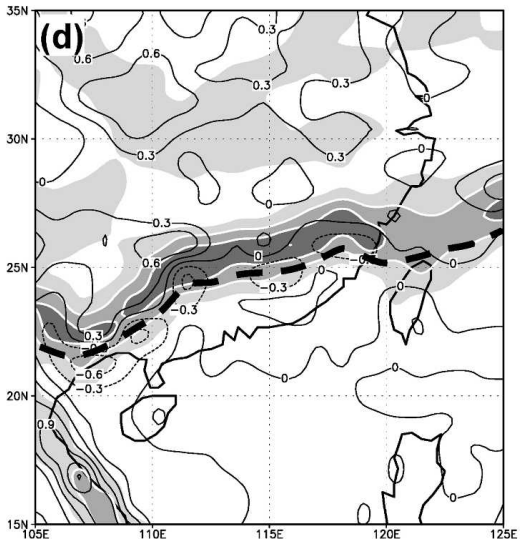

HEAT RATE 2000 Jun $1000 Z$

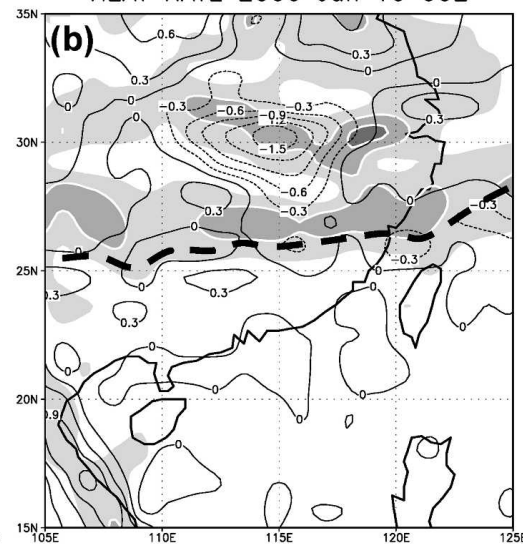

HEAT RATE 2000 Jun 12 o0Z

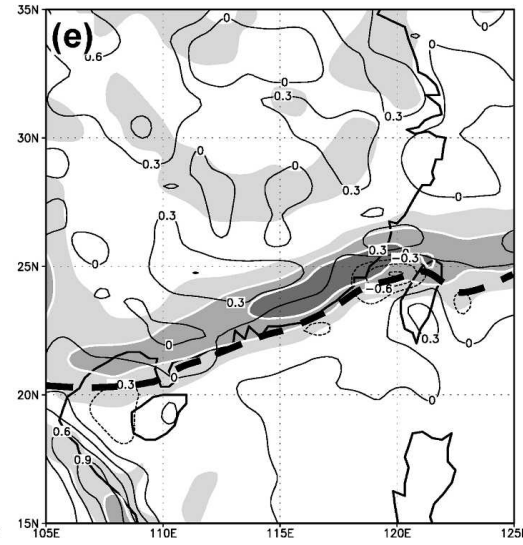

HEAT RATE 2000 Jun $1012 Z$

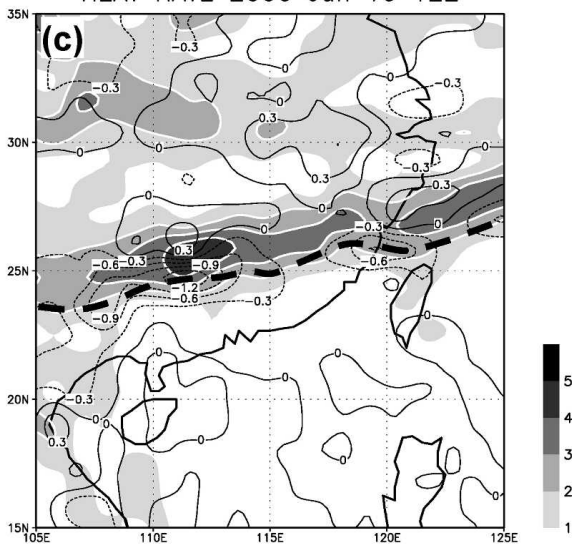

HEAT RATE 2000 Jun 13 o0Z

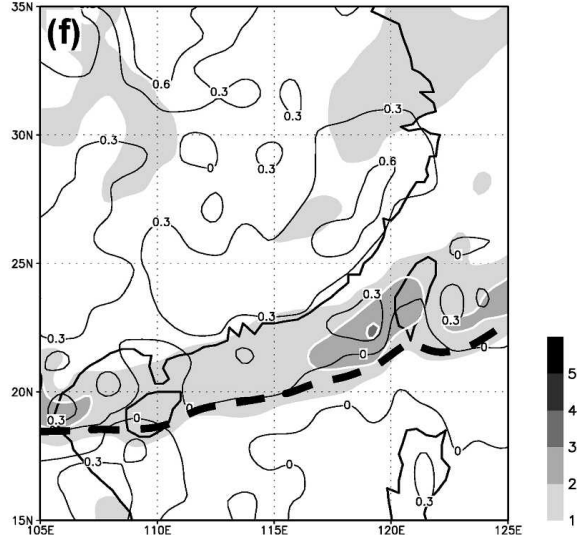

FIG. 14. Same as Fig. 13, but for heating rate $d \theta / d t\left(\mathrm{~K} \mathrm{~h}^{-1}\right.$; contours) associated with diabatic effects. Contour intervals are $0.3 \mathrm{~K} \mathrm{~h}^{-1}$, and solid (dashed) lines indicate positive (negative) values.

height on 10 June (Figs. 4b, 5b, 6a), a configuration favorable for baroclinic development. As the blocking high developed, low-level cold (warm) air moved south (north) to its immediate east (west; Fig. 6), and the ridge-trough system amplified concurrently at all levels (also Figs. 4, 5) in accordance with baroclinic development in earlier studies (e.g., Wang 1992; Lupo and Smith 1998; Tayanç et al. 1998). With low-level CAA over a vast area and upper-level confluence, geopotential heights rose over northern-central China to form a southward-extending ridge (Fig. 6). Eventually, the mei-yu trough merged with the main trough (Figs. 4, 6), forming a deep frontal zone with a strong $\theta$ gradient (Fig. 7).

Near the surface, the Sichuan high formed just behind the mei-yu front in association with the cold northerly flow (Figs. 1b, 6b), in a manner consistent with Chen and Jou (1988). A meridionally reversed temperature pattern developed and persisted into 13-14 June (Figs. 1b,c). Besides thermal advection, this thermal reversal at the surface was likely also maintained by stronger solar heating north of the front during day- time with clear skies to some extent, as suggested by the large areas of positive (though small) heating rate over central China in Fig. 14.

On 12 June, the blocking pattern had a wavelength of about $55^{\circ}-60^{\circ}$ in longitude (Fig. 4c), slightly larger than the composite of the Okhotsk Sea blocking obtained by Wang (1992) but comparable to the result of Hartmann and Ghan (1980). However, its location over Mongolia and northern China, being displaced so far westsouthwest from the Okhotsk Sea, was climatologically rare (e.g., Lejenäs and Økland 1983; Wang 1992; Pelly and Hoskins 2003) and occurred in June only once in 20 yr (this study). Obviously, the block's rare location allowed it to influence the front over southern China, while those near the usual Okhotsk Sea area tended to affect only fronts over Japan and central China (e.g., Ninomiya and Mizuno 1985, 1987; Ninomiya and Muraki 1986; Wang 1992).

\section{b. Effects of blocking on mei-yu front and frontogenesis}

From the analysis in section 3 , it is clear that the present mei-yu front was strongly influenced by the 
(a) 2000 Jun $800 Z$

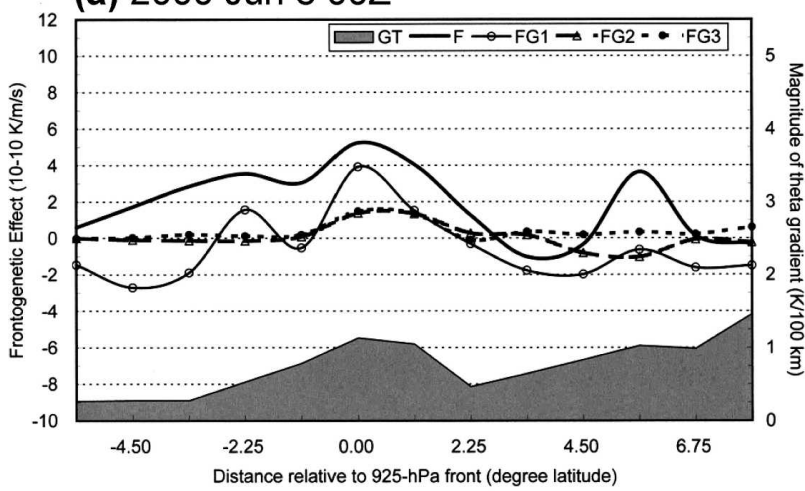

(c) 2000 Jun $1012 Z$

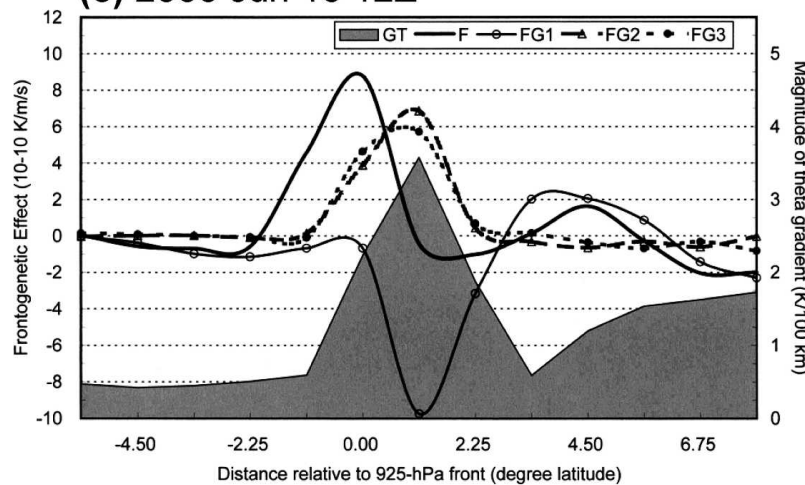

(e) 2000 Jun 12 00Z

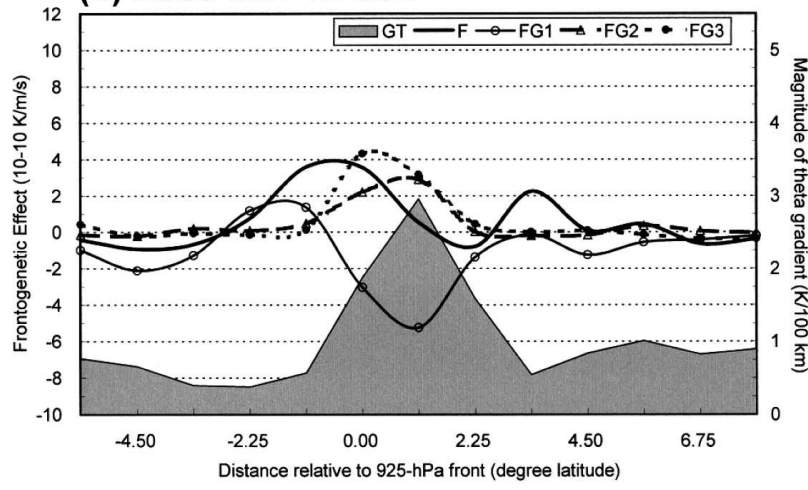

(b) 2000 Jun $1000 Z$

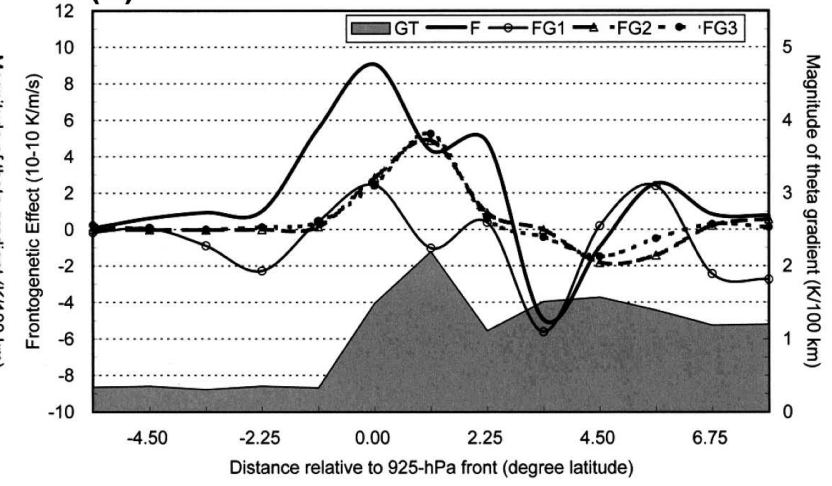

(d) 2000 Jun $1100 Z$

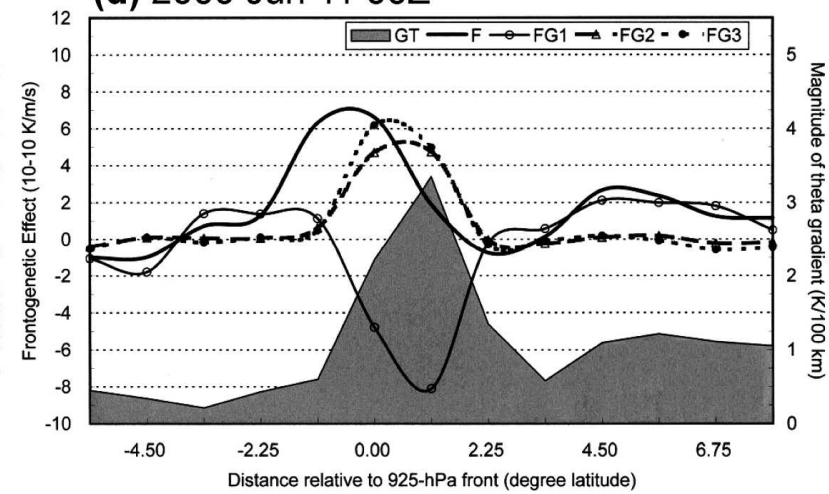

(f) 2000 Jun $1300 Z$

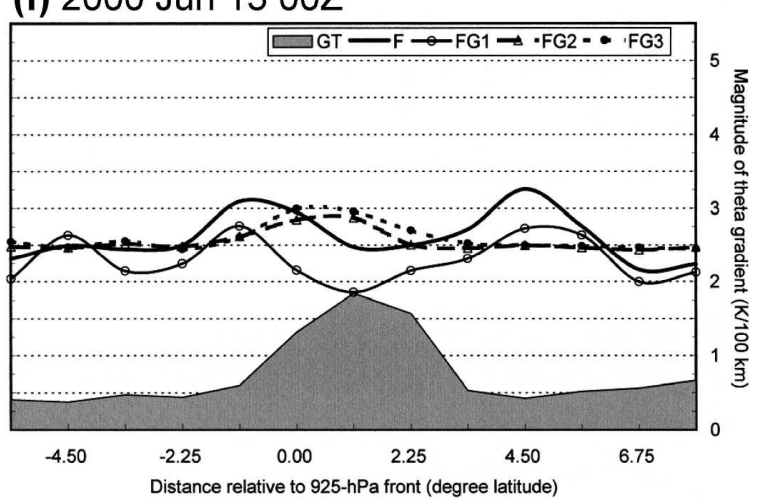

FIG. 15. Averaged values of frontogenetical function $(F)$, its contributing terms FG1, FG2, and FG3 (all in $10^{-10} \mathrm{~K} \mathrm{~m}^{-1} \mathrm{~s}^{-1}$; scale on lhs), and the magnitude of horizontal potential temperature gradient $\left(\left|\nabla_{H} \theta\right|\right.$; shaded; scale on rhs) at $925 \mathrm{hPa}$ from $-5.625^{\circ}$ (south) to $7.875^{\circ}$ (north) relative to the 925 -hPa front (at $0^{\circ}$ ) at (a) 0000 UTC 8 Jun, (b) 0000 UTC 10 Jun, (c) 1200 UTC 10 Jun, (d) 0000 UTC 11 Jun, (e) 0000 UTC 12 Jun, and (f) 0000 UTC 13 Jun 2000 . The average is performed over $108^{\circ}-120^{\circ} \mathrm{E}$, and curves for frontogenetical terms $(F, \mathrm{FG} 1, \mathrm{FG} 2$, and $\mathrm{FG} 3)$ are smoothed.

large-scale circulation associated with the blocking event. During the case period, a low-level confluent deformation field formed between the cold northerly surges induced by the block and the southwesterly flow at the perimeter of the subtropical high (Figs. $4,6,7)$, and the mei-yu front evolved, intensified, and subsequently moved deeply into the subtropics (Figs. 1, 9).

Through an analysis of the frontogenetical function in section 4, processes leading to the intensification/ weakening and propagation of the front, under the influence of the 500-hPa blocking episode, were examined. Except on 8 June, both the horizontal convergence (FG2) and deformation (FG3) were strongly positive along the frontal zone and acted to strengthen or maintain the front during the entire period, both over land and ocean (Figs. 11, 12, 15b-f). The peak of FG2 occurred in phase with the maximum frontal $\theta$ 
(a) 2000 Jun $800 Z$

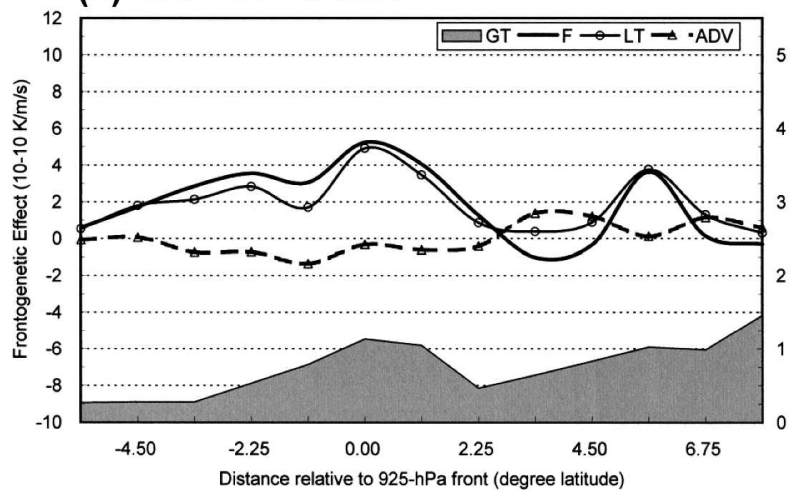

(c) 2000 Jun $1012 Z$

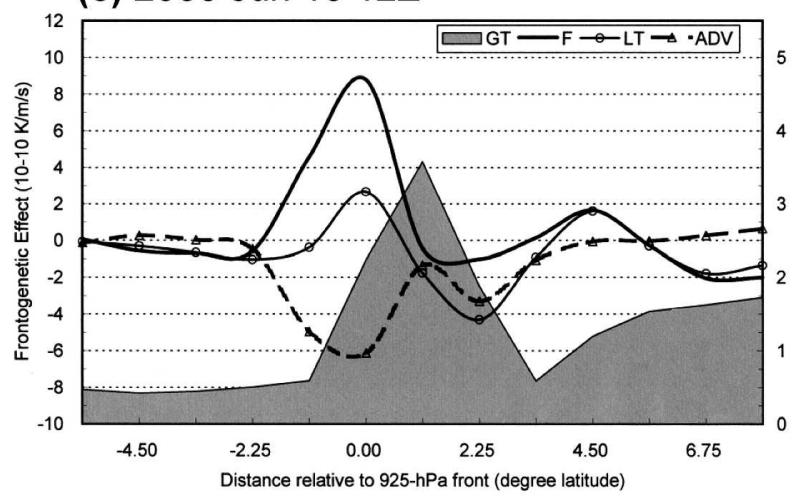

(e) 2000 Jun $1200 Z$

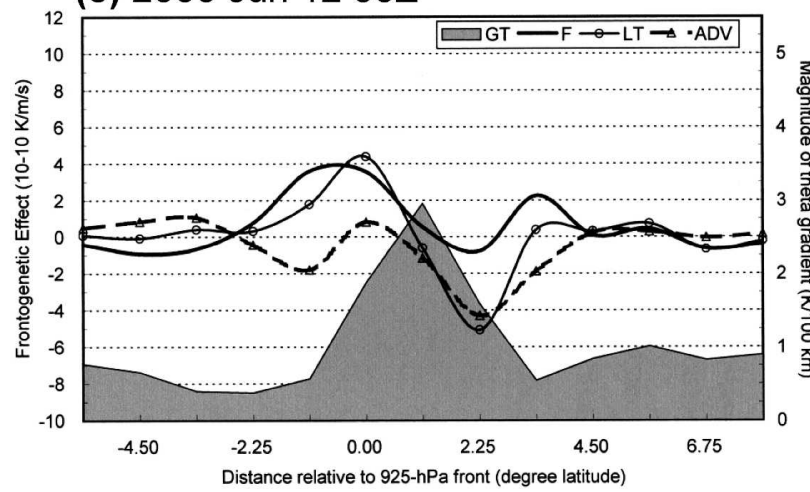

(b) 2000 Jun $1000 Z$

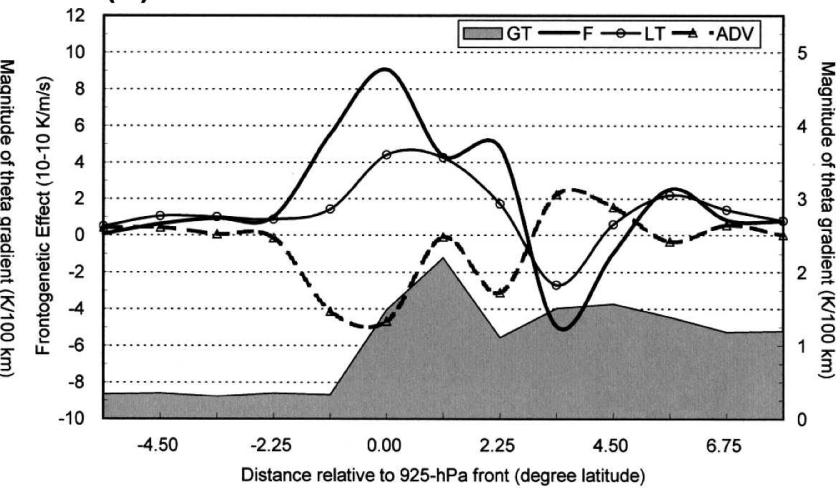

(d) 2000 Jun $1100 Z$

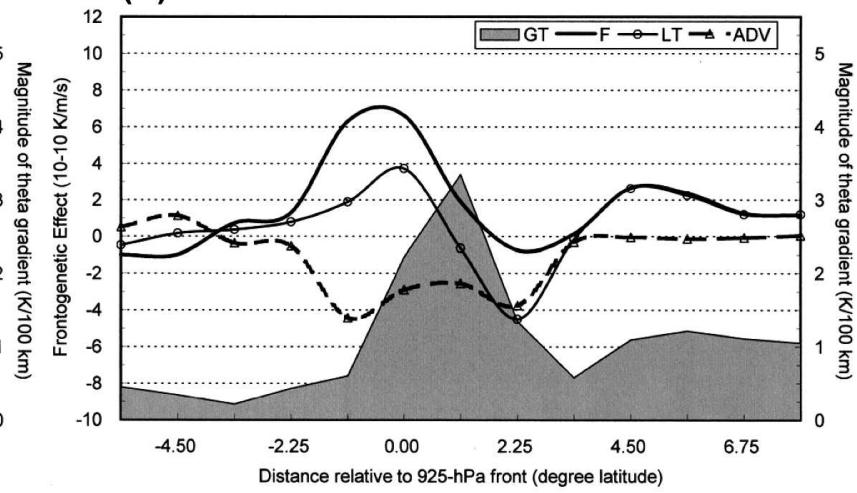

(f) 2000 Jun $1300 Z$

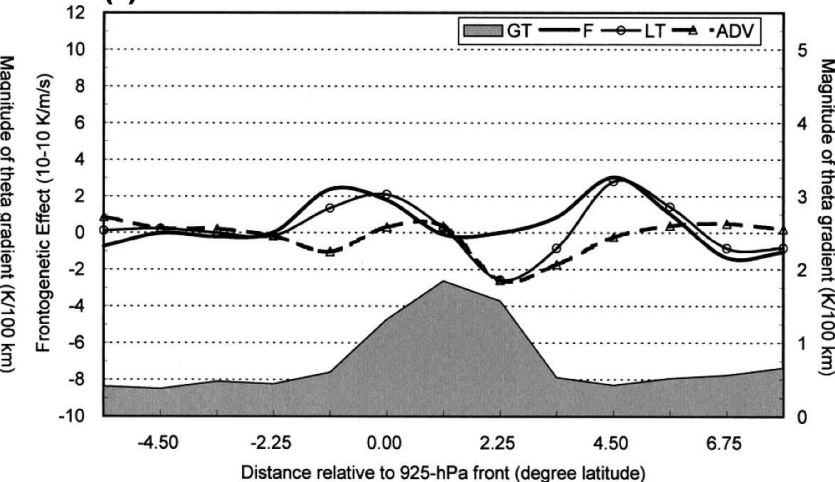

FIG. 16. Same as Fig. 15, but for averaged values of frontogenetical function $(F)$, LT $\left(\partial\left|\nabla_{H} \theta\right| / \partial t\right)$, and $\operatorname{ADV}\left(-\mathbf{V} \cdot \nabla_{H}\left|\nabla_{H} \theta\right|\right)$ of the magnitude of horizontal potential temperature gradient (all in $10^{-10} \mathrm{~K} \mathrm{~m}^{-1} \mathrm{~s}^{-1}$; scale on lhs), and magnitude of horizontal potential temperature gradient $\left(\left|\nabla_{H} \theta\right|\right.$; shaded; scale on rhs). Curves for $F$, LT, and ADV are smoothed.

gradient, and was the strongest (and exceeded FG3) at 1200 UTC 10 June (Fig. 15c) when the cold air (near $107^{\circ}-115^{\circ} \mathrm{E}$ ) reached about $30^{\circ} \mathrm{N}$ at $700 \mathrm{hPa}$ and the Sichuan high formed just behind the front (Figs. 1b, 6a). The northeasterly flow associated with the high, identified by Ding et al. (2001) as an important factor, helped tighten the postfrontal pressure gradient on 1011 June and produced additional convergence and thus frontogenesis near the surface. Both the effects of FG2 and FG3 over the northern Taiwan Strait were often strong (Figs. 11c-e, 12c-e), likely due, at least partially, to higher wind speed over the ocean (cf. Fig. 9).

The contribution from FG3 to frontogenesis can be understood as the increase in thermal gradient associated with flow deformation (with zero convergence) due to horizontal stretching (confluence) and/or shearing (e.g., Bluestein 1993, his section 2.3), and in the present case it was usually slightly stronger than FG2 except at 1200 UTC 10 June (Figs. 12, 15). During the blocking event (with concurrent development at all lev- 
els), large-scale deformation clearly existed in the lower troposphere near the front, between the prefrontal southwesterly and postfrontal northerly flow (section 3 ). As the postfrontal flow strengthened and pushed the mei-yu front southward (Figs. 9, 16), the deformation field and the band of positive FG3 values moved along as well (Figs. 7, 9c-f, 12c-f). During 11-12 June, the FG3 term peaked slightly ahead of the frontal zone, and thus also contributed toward the southward propagation of the mei-yu front (Figs. 15d,e). As discussed in section 3, the thermal gradient across the present meiyu front in southern China increased not only near the surface, but also throughout the lower-midlevels over 8-11 June (Figs. 1, 4-7), and such an evolution from a relatively weak, shallow front to a deep system with significant baroclinity was mainly through stretching (confluent) deformation and convergence.

\section{c. Frontal movement and the role of diabatic processes}

After the mei-yu front strengthened, the major effect of diabatic processes (FG1) was strongly frontolytic, which was counteracted by convergence and deformation (Figs. 13c-f, 15c-f). The frontolytic effect arose from a combination of evaporative cooling of frontal precipitation along the warm side and stronger surface sensible heat flux (and daytime radiative heating) along the cold side of the frontal zone (Fig. 14; section 4d). The combination of FG1, FG2, and FG3, as shown in Fig. 15, resulted in a distribution of the total frontogenetical function $F$ that peaked ahead of the frontal zone, thus contributing toward the southward propagation of the mei-yu front, in addition to the advection by the postfrontal cold air (Fig. 16) as discussed (also Smith and Reeder 1988).

\section{Conclusions}

During 8-11 June 2000, a blocking high developed at $500 \mathrm{hPa}$ over Mongolia and northern China (at $45^{\circ} \mathrm{N}$, $108^{\circ} \mathrm{E}$ ) and reached maturity on 12 June with a clear omega shape. The location of the block was climatologically rare, as it was the only event in the region during June 1981-2000. Associated with the block, the low-level mei-yu front over southern China intensified from a relatively shallow and weak system into a deep one with strong baroclinity. The front subsequently moved south and penetrated south of $20^{\circ} \mathrm{N}$ and well into the South China Sea on 13 June. At many sites over Taiwan, the frontal passage caused a temperature drop by more than $10^{\circ} \mathrm{C}$, which is also very unusual in June.
The development and evolution of this mei-yu front, under the influence of the blocking event, was diagnosed. Data included ECMWF $1.125^{\circ}$ gridded analyses, manually analyzed weather maps, satellite imagery, and surface observations. The 2D frontogenetical function of Ninomiya (1984) was computed at $925 \mathrm{hPa}$, and the contribution from different terms and the associated mechanisms were discussed. The major findings are summarized below.

1) The evolution of the blocking event over Mongolia and northern China was consistent with baroclinic development. As the upper-level ridge-trough system amplified, concurrent development took place throughout the troposphere. Low-level geopotential heights rose in central (then southern) China, accompanied by CAA at the southeastern/southern quadrant of the upper-level high. Then, the lowlevel ridge gradually extended southward into lower latitudes, and a cold surface high pressure system formed over the Sichuan basin just behind the meiyu front.

2) Associated with the block, cold air penetrated southward at low levels while warm air moved north to the west of the ridge, creating a reversed thermal pattern. During this period, large-scale confluence/ deformation existed over southern China between the northerly flow induced by the block and the prefrontal southwesterly flow at the perimeter of the subtropical high, and provided the basic mechanism for mei-yu frontogenesis.

3) The unusual location of the block, to the far westsouthwest of the usual Okhotsk Sea area, allowed it to affect the mei-yu front over southern China, and subsequently caused the front to move offshore and penetrate well into the subtropics (south of $20^{\circ} \mathrm{N}$ ) in June.

4) The frontogenetical function calculation at $925 \mathrm{hPa}$ indicated that the intensification and maintenance of the mei-yu front during 10-12 June were attributed to both deformation and convergence, and the former was usually slightly stronger. Diabatic processes, on the other hand, were strongly frontolytic because of the combination of evaporative cooling of frontal precipitation at the warm side and stronger sensible heat transfer as well as stronger daytime solar heating over cloud-free areas at the cold side of the front.

5) Because positive effects of deformation and convergence (to a lesser degree) were located ahead of the counteraction from diabatic processes, the total frontogenesis peaked slightly ahead of the frontal zone. Thus, the combined effect had a net contribu- 
tion to the southward propagation of the front in addition to advection in the present case.

6) When the mei-yu front moved offshore into the South China Sea, frontolysis from sensible heat flux over the ocean dominated over the frontogenesis of deformation and convergence along the frontal zone. The frontal thermal gradient hence weakened.

Acknowledgments. The authors are grateful to editor Dr. David M. Schultz of CIMMS/NSSL, reviewer Dr. Ron McTaggart-Cowan, and the other anonymous reviewers for their invaluable and constructive suggestions and comments that helped improve the content and presentation of this paper. The assistance of Mr. J.-S. Yang, Mr. C.-S. Chang, and Mr. Mark I.-M. Wang during the preparation of the manuscript is also acknowledged. This study was supported by the National Science Council (NSC) of Taiwan, under Grants NSC95-2111-M-002-001, NSC-95-2111-M-002-016, and NSC-95-2625-Z-034-001.

\section{REFERENCES}

Bluestein, H. B., 1993: Synoptic-Dynamic Meteorology in Midlatitudes. Vol. 2. Oxford University Press, 594 pp.

Carlson, T. N., 1991: Mid-Latitude Weather Systems. Routledge, 507 pp.

Charney, J. G., J. Shukla, and K. C. Mo, 1981: Comparison of barotropic blocking theory with observation. J. Atmos. Sci., 38, 762-779.

Chen, C.-K., and C.-Y. Tsay, 1980: Mei-yu systems which affect northern Taiwan (in Chinese with English abstract). Atmos. Sci., 7, 49-58.

Chen, G. T.-J., 1983: Observational aspects of Mei-yu phenomena in subtropical China. J. Meteor. Soc. Japan, 61, 306-312.

, 1994: Large-scale circulations associated with the East Asian summer monsoon and the Mei-yu over south China and Taiwan. J. Meteor. Soc. Japan, 72, 959-983.

— , and C.-P. Chang, 1980: The structure and vorticity budget of an early summer monsoon trough (Mei-Yu) over southeastern China and Japan. Mon. Wea. Rev., 108, 942-953.

_ , and B. J.-D. Jou, 1988: Interannual variations of the relevant large-scale circulations during the Taiwan Mei-yu seasons. Pap. Meteor. Res., 11, 119-147.

Chen, Y.-L., 1993: Some synoptic-scale aspects of the surface fronts over southern China during TAMEX. Mon. Wea. Rev., 121, 50-64.

— , and N. B.-F. Hui, 1990: Analysis of a shallow front during the Taiwan Area Mesoscale Experiment. Mon. Wea. Rev., 118, 2649-2667.

— , and — 1992: Analysis of a relatively dry front during the Taiwan Area Mesoscale Experiment. Mon. Wea. Rev., 120, 2442-2468.

—_, Y.-X. Zhang, and N. B.-F. Hui, 1989: Analysis of a surface front during the early summer rainy season over Taiwan. Mon. Wea. Rev., 117, 909-931.

Cho, H.-R., and G. T.-J. Chen, 1995: Mei-yu frontogenesis. $J$. Atmos. Sci., 52, 2109-2120.
Ding, Y.-H., 1992: Summer monsoon rainfalls in China. J. Meteor. Soc. Japan, 70, 337-396.

_, Y. Zhang, Q. Ma, and G. Hu, 2001: Analysis of the largescale circulation features and synoptic systems in East Asia during the intensive observing period of GAME/HUBEX. $J$. Meteor. Soc. Japan, 79, 277-300.

Hartmann, D. L., and S. J. Ghan, 1980: A statistical study of the dynamics of blocking. Mon. Wea. Rev., 108, 1144-1159.

He, H., J. W. McGinnis, Z. Song, and M. Yanai, 1987: Onset of the Asian summer monsoon in 1979 and the effect of the Tibetan Plateau. Mon. Wea. Rev., 115, 1966-1995.

Hoskins, B. J., and F. P. Bretherton, 1972: Atmospheric frontogenesis models: Mathematical formulation and solution. J. Atmos. Sci., 29, 11-37.

Kato, K., 1985: On the abrupt change in the structure of the Baiu front over the China continent in late May of 1979. J. Meteor. Soc. Japan, 63, 20-35.

Koch, S. E., J. T. McQueen, and V. M. Karyampudi, 1995: A numerical study of the effects of differential cloud cover on cold frontal structure and dynamics. J. Atmos. Sci., 52, 937-964.

Kuo, Y.-H., and G. T.-J. Chen, 1990: The Taiwan Area Mesoscale Experiment (TAMEX): An overview. Bull. Amer. Meteor. Soc., 71, 488-503.

Lau, K.-M., G. J. Yang, and S. H. Shen, 1988: Seasonal and intraseasonal climatology of summer monsoon rainfall over East Asia. Mon. Wea. Rev., 116, 18-37.

Lejenäs, H., and H. Økland, 1983: Characteristics of northern hemispheric blocking as determined from a long time series of observational data. Tellus, 35A, 350-362.

— , and R. A. Madden, 1992: Traveling planetary-scale waves and blocking. Mon. Wea. Rev., 120, 2821-2830.

Lupo, A. R., and P. J. Smith, 1998: The interactions between a midlatitude blocking anticyclone and synoptic-scale cyclones that occurred during the summer season. Mon. Wea. Rev., 126, 502-515.

Miller, J. E., 1948: On the concept of frontogenesis. J. Meteor., 9, 169-171.

Mullen, S. L., 1987: Transient eddy forcing of blocking flows. $J$. Atmos. Sci., 44, 3-22.

Nakamura, H., and J. M. Wallace, 1993: Synoptic behavior of baroclinic eddies during the blocking onset. Mon. Wea. Rev., 121, 1892-1903.

_, M. Nakamura, and J. L. Anderson, 1997: The role of highand low-frequency dynamics in blocking formation. Mon. Wea. Rev., 125, 2074-2093.

Ninomiya, K., 1984: Characteristics of Baiu front as a predominant sub-tropical front in the summer northern hemisphere. J. Meteor. Soc. Japan, 62, 880-894.

_ northeastern Japan caused by northeasterly wind from polar maritime airmass. Part I. EOF analysis of temperature variation in relation to the large-scale situation causing the cold summer. J. Meteor. Soc. Japan, 63, 845-857.

_ , and H. Muraki, 1986: Large-scale circulations over East Asia during Baiu period of 1979. J. Meteor. Soc. Japan, 64, 409-429.

— Japan in 1951-1980. J. Meteor. Soc. Japan, 65, 115-127.

Pelly, J. L., and B. J. Hoskins, 2003: A new perspective on blocking. J. Atmos. Sci., 60, 743-755.

Petterssen, S., 1936: Contribution to the theory of frontogenesis. Geofys. Publ., 11 (6), 1-27.

Quiroz, R. S., 1987: Traveling waves and regional transitions in 
blocking activity in the northern Hemisphere. Mon. Wea. Rev., 115, 919-935.

Rex, D., 1950: Blocking action in the middle troposphere and its effect upon regional climate. II. The climatology of blocking action. Tellus, 2, 275-301.

_ 1951: The effect of Atlantic blocking action upon European climate. Tellus, 3, 100-112.

Sanders, F., 1999a: A proposed method of surface map analysis. Mon. Wea. Rev., 127, 945-955.

_ 1999b: A short-lived cold front in the southwestern United States. Mon. Wea. Rev., 127, 2395-2403.

Schultz, D. M., 2005: A review of cold fronts with prefrontal troughs and wind shifts. Mon. Wea. Rev., 133, 2449-2472.

_ 2007: Perspectives on Fred Sanders's research on cold fronts. The Fred Sanders Symposium Volume Two, Meteor. Monogr., Amer. Meteor. Soc., in press. [Available online at http://www.cimms.ou.edu/ schultz/sanders/sanders.pdf.]

— caused by dry subcloud air in northern Utah during the Intermountain Precipitation Experiment (IPEX). Mon. Wea. Rev., 131, 2222-2246.

Segal, M., W. L. Physick, J. E. Heim, and R. W. Arritt, 1993: The enhancement of cold-front temperature contrast by differential cloud cover. Mon. Wea. Rev., 121, 867-873.

Shapiro, M. A., and D. A. Keyser, 1990: Fronts, jet streams, and the tropopause. Extratropical Cyclones: The Erik Palmén Memorial Volume, C. W. Newton and E. O. Holopainen, Eds., Amer. Meteor. Soc., 167-191.
Shikin, E. V., and A. I. Plis, 1995: Handbook on Splines for the User. CRC Press, $221 \mathrm{pp}$.

Shukla, J., and K. C. Mo, 1983: Seasonal and geographical variation of blocking. Mon. Wea. Rev., 111, 388-402.

Sinclair, M. R., and R. L. Elsberry, 1986: A diagnostic study of baroclinic disturbances in polar air streams. Mon. Wea. Rev. 114, 1957-1983.

Smith, R. K., and M. J. Reeder, 1988: On the movement and lowlevel structure of cold fronts. Mon. Wea. Rev., 116, 19271944.

Tao, S., and L. Chen, 1987: A review of recent research on the East Asian summer monsoon in China. Monsoon Meteorology, C.-P. Chang and T. N. Krishnamurti, Eds., Oxford University Press, 60-92.

Tayanç, M., M. Karaca, and H. N. Dalfes, 1998: March 1987 cyclone (blizzard) over the eastern Mediterranean and Balkan region associated with blocking. Mon. Wea. Rev., 126, 30363047.

Tibaldi, S., E. Tosi, A. Navarra, and L. Pedulli, 1994: Northern and Southern Hemisphere seasonal variability of blocking frequency and predictability. Mon. Wea. Rev., 122, 19712003.

Trier, S. B., D. B. Parsons, and T. J. Matejka, 1990: Observations of a subtropical cold front in a region of complex terrain. Mon. Wea. Rev., 118, 2449-2470.

Wang, Y., 1992: Effects of blocking anticyclones in Eurasia in the rainy season (Meiyu/Baiu season). J. Meteor. Soc. Japan, 70, 929-951. 